NBER WORKING PAPER SERIES

\title{
HOMEOWNERSHIP AND UNEMPLOYMENT : THE ROLES OF LEVERAGE AND PUBLIC HOUSING
}

\author{
Paul Flatau \\ Matt Forbes \\ Patric H. Hendershott \\ Gavin Wood \\ Working Paper 10021 \\ http://www.nber.org/papers/w10021 \\ NATIONAL BUREAU OF ECONOMIC RESEARCH \\ 1050 Massachusetts Avenue \\ Cambridge, MA 02138 \\ October 2003
}

Earlier versions of this paper were presented at the 2003 AREUEA Annual and MidYear Meetings, both in Washington, DC. This study is part of a larger Australian Housing and Urban Research Institute (AHURI) project: What Drives Housing Outcomes in Australia? Understanding the Role of Aspirations, Household Formation, Economic Incentives and Labour Market Interactions. The views expressed herein are those of the authors and are not necessarily those of the National Bureau of Economic Research.

(C)2003 by Paul Flatau, Matt Forbes, Patric H. Hendershott, and Gavin Wood. All rights reserved. Short sections of text, not to exceed two paragraphs, may be quoted without explicit permission provided that full credit, including (C) notice, is given to the source. 
Homeownership and Unemployment: The Roles of Leverage and Public Housing

Paul Flatau, Matt Forbes, Patric H. Hendershott, and Gavin Wood

NBER Working Paper No. 10021

October 2003

JEL No. J64, R2

\section{ABSTRACT}

Oswald hypothesizes that regions and countries with high homeownership rates will experience higher natural rates of unemployment and that rising homeownership in OECD countries since the 1960s provides a key explanation for the rise in the natural rate of unemployment over the same time period. Recent tests of the Oswald thesis have found the opposite. This study differs from earlier ones both by considering different states of ownership (degrees of leverage) and types of tenancy (private, public, and rent-free) and by examining data from Australia, rather than the U.S.

We demonstrate that the recent anti-Oswald results are the result of(1) highly leveraged owners having a greater incentive to remain employed and to become reemployed more rapidly that outright owners and (2) those paying below-market rents having a lower incentive to avoid unemployment or become reemployed than those paying market rents. The only positive Oswald result is that females who are outright owners have significantly slower exits from unemployment. Overall, homeownership does not increase unemployment.

Finally, in line with expectations but in contrast to some earlier studies, our results indicate a significant impact of the predicted replacement ratio (unemployment benefits to wage if reemployed) on unemployment behavior. Persons with a higher predicted ratio are significantly more likely to become unemployed, and unemployed females with a higher predicted replacement ratio have longer unemployment spells than those with lower predicted ratios.

Paul Flatau

Economics Department

Murdoch University

Murdoch, WA 6150

Australia

plta@central.murdoch.edu.au

Matt Forbes

Economics Department

Murdoch University

Murdoch, WA 6150

Australia
Patric H. Hendershott

Cnetre for Property Research

University of Aberdeen Business School

Aberdeen AB24 3UF, Scotland

and NBER

phh3939@uslink.net

\section{Gavin Wood}

Economics Department

Murdoch University

Murdoch, WA 6150

Australia

wood@central.murdoch.edu.au 


\section{Introduction}

Andrew Oswald $(1996,1997)$ has argued forcefully, based upon analysis of time series and crosssection data for OECD countries and regions within selected OECD countries, that homeownership causes unemployment. He concludes that if the rate of homeownership rises by five percentage points, unemployment will rise by one percentage point, an effect so large that it would place homeownership at the center of explanations for the rise in the natural rate of unemployment since the 1960s in OECD countries. Oswald (1996, p.2) suggests '[M]ass unemployment exists because of a secular change that has happened in all but a few Western housing markets - the rise of homeownership and the decline of private renting'. ${ }^{1}$

Two straight-forward rationales have been offered for the Oswald result. First, homeowners face higher selling and buying costs compared to renters when they consider a move to a new location to accept a job offer. As a result, homeowners may be more likely to become unemployed (may be less willing to accept job transfers to or job opportunities in distant locations) and may remain unemployed longer (have a greater reluctance to search in distant locations requiring a move). Second, homeowners may, through their voting power in local government, enforce restrictive planning and land development laws depressing employment options and thus increasing unemployment.

Oswald's claim about the size and direction of the relationship between unemployment and homeownership has attracted the attention of both housing and labor economists. A number of studies have mimicked Oswald's aggregate regional analysis, analyzing data from different regions and adding additional covariates. Nickell and Layard (1999) add covariates in an analysis of the original OECD country data. Green and Hendershott (2001) and Partridge and Rickman (1997)

\footnotetext{
${ }^{1}$ The rise in secular unemployment since the 1960s has been far more prominent in Western Europe than in the U.S. a fact that has prompted considerable debate among labor and macroeconomists (see Nickell, 1998).
} 
both analyze US state data, adjusting for age composition and other factors, and Pehkonen (1997) examines Finnish data. All of these studies find confirmation of Oswald's result, with the magnitude of the response ranging from a one to two percentage point increase in the unemployment rate for a ten percentage point increase in the homeownership rate.

Three studies have tested the Oswald thesis using US micro datasets. ${ }^{2}$ Goss and Phillips (1997) examine the impact of housing equity levels on the duration of unemployment using the 1986 Panel Study of Income Dynamics and find that homeownership reduces the duration of unemployment as compared with other tenures with the effect stronger for mortgagees as compared with outright owners. ${ }^{3}$ Coulson and Fisher (2002) find that homeowners have significantly lower probabilities of being unemployed and typically earn significantly higher wages than renters. They also find that homeownership exerts a significant negative influence upon the length of the unemployment spell. Green and Hendershott (2002) examined the duration of unemployment of roughly 2500 Americans who became unemployed during the 1985-92 period. In a two-component analysis, they first estimate a probit explaining homeownership and then relate the duration of unemployment to predicted homeownership. Rather than Oswald's predicted positive relationship, they, too, find a negative relationship.

How can we rationalize these seemingly counter intuitive results? While the logic of Oswald's argument seems impeccable if we are comparing outright owners and private renters, some owners are highly leveraged and some renters occupy public housing or live rent-free with relatives. Homeowners with weak housing equity positions may require quick re-employment to

\footnotetext{
${ }^{2}$ Van Leuvensteijn and Koning (2000) study a number of Oswald's sub-hypotheses regarding labour force mobility using micro-panel data from the Netherlands.

${ }^{3}$ Goss and Phillips' (1997) study was published shortly after Oswald's (working) paper was released and undertaken in ignorance of it. Nevertheless, the authors' tests do in practice represent tests of the Oswald thesis.
} 
enable them to continue making their mortgage payments. ${ }^{4}$ Thus they may specify lower reservation wages than equivalently qualified renters, leading to the greater possibility of shorter durations of unemployment (Goss and Phillips, 1997).

The presence of public housing with tenants paying long-term below-market rents and of free-renters also confounds the analysis. Hendershott and $\mathrm{Hu}$ (1982) showed that significantly leveraged owners with below-market financing rates should be reluctant to move if that requires giving up their below-market financing (see Quigley, 1987, for empirical support). Similarly, public housing tenants and free-renters should be reluctant to give up their below-market rents. A large literature has found UK public tenants to be less mobile between regions and to experience higher levels of unemployment (Engleman, 1977; Bover, Muellbauer, and Murphy, 1989; Hughes and McCormick, 1981, 1985, 1987; McCormick, 1983; Minford, Ashton, and Peel, 1988).

The present study employs an Australian micro dataset that is particularly strong both on the labor market position of the respondents and their housing status. This allows more refined tests of more sophisticated versions of the Oswald thesis in a different country setting. We also employ the predicted ratio of unemployment benefits to wages if employed as an explanatory variable in the analyses, a variable missing from earlier analyses. We provide strong evidence that our counter-Oswald results are due to the behavior of leveraged owners and public housing tenants. In fact, when we compare outright owners (rather than leveraged owners) with private renters (rather that public renters), we find strong evidence, particularly for females that renters are slower to become reemployed than owners. More specifically, female outright owners and public housing occupants are equally less likely to exit unemployment as rapidly as private renters and owners with mortgages.

\footnotetext{
${ }^{4}$ Moreover, homeowners with large mortgages can be subject to negative equity problems resulting in significant housing lock-in effects (see Archer, Ling and McGill, 1996, Caplin, Freeman and Tracy, 1997 and Henley, 1998).
} 
Four tests are employed to deduce the impact of homeownership, public housing and leverage on unemployment. The first two tests focus solely on the relationship between the aggregate housing tenure type 'homeownership' and unemployment. First, we estimate a probit explaining the probability of being unemployed using (actual or predicted) homeownership as a determinant (the choice between the two options being made on a prior test for exogeneity of homeownership). Second we estimate a hazard equation explaining the factors influencing duration of a spell of unemployment. Our final two tests move beyond this broad specification to consider, in turn, the role of leverage in influencing the incidence and duration of unemployment of homeowners and the impact of multiple housing tenures (outright owners, mortgages, public renters, private renters and free renters on unemployment outcomes).

The remainder of the paper contains four sections. In Section 2, we present the models to be estimated. These include probits for being unemployed and a hazard for the duration of unemployment. Section 3 elaborates on the data used in the study. The data used in this study are drawn from the pooling of four consecutive Australian cross-section surveys from the mid to late 1990s (the 1994-97 Surveys of Income and Housing Costs, SIHC). These data provide rich housing, labor market and income data and importantly include a tracking of the respondent's labor force position over an eight-month period. The latter feature injects a longitudinal module into the data and is used in our unemployment spell analysis. Section 4 provides our results on unemployment and the duration of unemployment. We briefly summarize and look toward future work in Section 5.

\section{The Models}

Homeownership can correlate with the probability of becoming unemployed or the duration of unemployment either because homeownership really matters or because it is correlated with other 
unobservable factors that help determine both tenure choice and the probability or duration of unemployment. For example, the user cost of a household with a long expected holding period is lower than that of one with a shorter expected length of stay due to the longer amortization of upfront stamp duties (taxes) and back-out brokerage fees. One reason for long expected lengths of stay is a greater desire to retain proximity to family members and friends. If such owners become unemployed, they will tend to remain unemployed longer than renters who become unemployed, but it is due to their wish to remain proximate to family rather than being caused by their tenure status.

There is, therefore, no guarantee that homeownership is an exogenous determinant of unemployment and we need to directly test for exogeneity in the homeownership effect on both the probability of unemployment and its duration. Our test is a simple extended regression test in which actual homeownership and a prediction error term (the difference between actual homeownership and predicted homeownership) are entered in relevant preliminary models. Because the null hypothesis of a zero coefficient on the error term is rejected, we use predicted homeownership in our final equation (i.e., an unemployment probit, and an unemployment spell hazard model).

The probability of being a homeowner is expressed as:

Probit: $\quad O_{i}=\mathrm{P}\left(\beta_{1} Y_{i}+\boldsymbol{\beta}_{2} \boldsymbol{J}_{i}+\mu_{\mathrm{i}}\right)$

where $\mathrm{i}$, represents the decision-making unit and $\mathrm{O}_{\mathrm{i}}$ indicates tenure choice, taking a value 1 if the unit is a home owner and 0 otherwise. Explanatory variables include real income (Y) and a matrix (J) of demographic identifiers (importantly age ranges, but also country of birth, race, gender, marital status), human capital variables (education outcomes) and location dummies (divided into 
capital city and rest of the state dummies). As elsewhere, house prices and rents in Australia differ markedly across geographic location and thus geographic locators provide proxies for housing cost determinants of tenure choice.

While otherwise unremarkable, one feature of our tenure choice model needs to be emphasized. We assume that the tenure choice decision-making unit is the 'income unit' rather than the 'household', the common approach in most tenure choice models. The income unit (a unit of analysis used in social policy analyses in the Australian context) is defined as one person or a group of related persons who reside within a single residential dwelling whose command over income is assumed to be common. ${ }^{5}$ The household comprises all persons in a given dwelling. In most cases, households and income units are one and the same entity. A single person, living alone, is both an income unit and a household; so too the couple with or without dependent children, in which case income is aggregated and where it is inappropriate to combine the attributes of the couple (e.g., age) we simply take the attributes of the head (the person with the highest income) of the couple (thus the predicted ownership of head and spouse will be equal). Households and income units are different (and the predicted probabilities of ownership will differ) when unrelated people live together in the same dwelling or when children grow up but remain in the family home even when they are no longer (notionally) dependent on their parents. The former are assumed to split the rent unless the data indicate otherwise; the latter are assumed to be living rent free. Each unrelated person in a household is making an independent housing tenure decision as is the young adult still living at home.

\footnotetext{
${ }^{5}$ Following the practice of the Australian Bureau of Statistics' (ABS) - the data manager of the survey data used in this study - income sharing is assumed to take place between married (registered or de facto) couples and between parents and dependent children (see ABS, 1999, p. 16). The ABS defines dependent children 'as all persons aged under 15 years and persons aged 15-24 years who are full-time students, live with a parent or guardian and do not have a spouse or offspring of their own living with them' (see ABS, 1999, p. 15).
} 


\section{Probability of Being Unemployed}

The probability of an individual being unemployed is expressed as

Probit $\quad \mathrm{U}_{i}=\mathrm{P}\left(\gamma_{1} O^{*}{ }_{i}+\gamma_{2} R_{i}+\gamma_{3}{ }^{\prime} \boldsymbol{S}_{\boldsymbol{t}}+\gamma_{4}{ }^{\prime} \boldsymbol{\theta}_{\boldsymbol{t}}+\mu_{\mathrm{i}}\right)$

where $O_{i}^{*}$ is predicted/actual homeownership, $R_{i}$ is the predicted replacement ratio, $S$ is a matrix of socio-demographic determinants of unemployment and $\boldsymbol{\theta}_{\boldsymbol{t}}$ is a matrix of quarterly time dummies that account for time-related shocks (recall that our data are pooled cross-section). To determine whether or not predicted or actual homeownership should be used for estimation purposes, we include in a preliminary model actual homeownership and the prediction error term. The latter term is equal to the actual housing tenure state ( 1 for the home owner and 0 for the non-home owner) less the predicted probability of being a homeowner (from the tenure choice probit model equation 1). For the homeowner, the term is positive and increases as the predicted probability of

being a renter rises $\left(1-\hat{O}_{i}\right)$. For the non-home owner, the term is negative and in this case the absolute value increases as the error rises $\left(0-\hat{O}_{i}\right)$.

A key economic determinant of the probability of being unemployed is the predicted replacement ratio of the individual. This ratio is measured as the weekly unemployment benefit an individual is predicted to receive relative to their predicted weekly wage. The higher the replacement ratio, the lower is the opportunity cost of being unemployed (the smaller is the relative loss in wages) and consequently the higher the expected probability of being unemployed. Estimates of expected earnings are based on a standard human capital OLS regression (estimated 
separately for women and men), which includes age categories to proxy for potential labor force experience and educational qualifications. ${ }^{6}$

As opposed to Coulson and Fisher (2002) and Green and Hendershott (2002), we have measures of unemployment benefits in the data and use these estimates to predict an unemployment benefit to all persons, which accounts for non-wage income and the sociodemographic determinants that enter the administrative rules that apply to unemployment benefits in Australia. All other things being equal, unemployment benefits are higher for those over age 21, those with more children and those with lower wealth and private income. Income and assets tests reduce the level of the benefit until the payment drops to zero. A rental subsidy applies to unemployed private renters. This is unlike the contributory U.S. unemployment insurance benefit system where benefits are positively related to past earnings. Another crucial difference between the two systems is that in the U.S. there is benefit exhaustion whereas in Australia there is no direct benefit exhaustion but an emphasis on the unemployment benefit recipient complying with job search and work-for-benefit guidelines as the spell of unemployment lengthens. The vector $\boldsymbol{\theta}_{\boldsymbol{t}}$ includes quarterly time dummies that will be used to capture shocks in real economic activity that affect the time path of unemployment.

The probit model of unemployment is based on the individual unit of analysis and includes all persons in the labor force. We delete persons aged 65 and over and dependent children aged 1524. The probit model is then estimated separately for men and for women. The inverse Mills ratios $(\varphi / \Phi)$ from these equations will be used in the unemployment duration hazard functions to correct for sample selection bias.

\footnotetext{
${ }^{6}$ Our results are not reported in this paper. Educational qualifications exert their anticipated strong positive impact on wages, as does potential labor market experience (age classifications).
} 


\section{Duration of Unemployment}

Under Oswald's thesis, homeownership leads to higher unemployment. Given the key transmission mechanism through which homeownership is expected to lead to higher unemployment - the relative immobility of homeowners - we would expect longer durations of unemployment as well. In this section, we model the duration of unemployment using a hazard analysis. But before discussing our hazard model, we make clear how we measure spells of unemployment; an obvious requirement but one that is not always met in studies of unemployment.

Two questions need to be answered regarding spells of unemployment. First, when does a spell of unemployment begin and end? Second, how do we deal with the missing information problem evident in all data sets when spells of unemployment begin prior to the opening of a data set's window or end after that window is closed? $?^{7}$ The latter problem is one of censorship bias that cannot be overcome but can be ameliorated through sound statistical techniques, while the former is an issue in the meaning and characterization of unemployment spells themselves.

The population divides itself into three states: employed, unemployed and not in the labor force (or NILF). This means that a spell of unemployment can begin as a result either of an individual entering unemployment from the state of employment (full time, FtE, or part time, PtE) or from the NILF labor force position. A person who enters unemployment from employment is a job loser. Some data sets can distinguish between voluntary job quits and involuntary retrenchments but the SIHC cannot. Likewise, an individual can exit from unemployment to the NILF state or to employment. An exit to employment can be further broken down to an exit to part-time employment or an exit to full-time employment (over 35 hours per week of employment). There are good grounds for placing emphasis on the last of these transitions (that to full-time

\footnotetext{
${ }^{7}$ A dataset's window refers to the period of direct reporting of (by) a respondent's actions and outcomes.
} 
employment) because it represents, for most unemployed people, the best possible labor market transition.

An exit to the NILF state, on the other hand, can be difficult to interpret. For some, the transition from unemployment to the NILF category represents the least desired transition as it reflects a discouraged job seeker effect (i.e., the individual is losing the desire and attachment to work to continue the search process). An exit to the NILF state could, however, represent a period of retooling through full-time education and training or a decision to undertake full-time care for dependent children or aged parents. Each of these transitions may be the most desired transition.

Transitions from and to unemployment are illustrated in Figure 1a. The right and left censoring of unemployment spells is illustrated in Figure 1b. A spell may begin before the data window of the relevant data set and is referred to as a left-censored spell. Only retrospective questions put to respondents would ever enable researchers to determine the beginning of the spell (and that does not occur with the dataset used in the present circumstance). The origin of spells is, however, known when it begins after the start of a survey's data window (i.e., a non-left-censored spell). When a spell of unemployment has not ended prior to the end of a survey's data window the spell is right censored. We do not know when such spells will end.

\section{Figure 1a Labor Force Transitions}

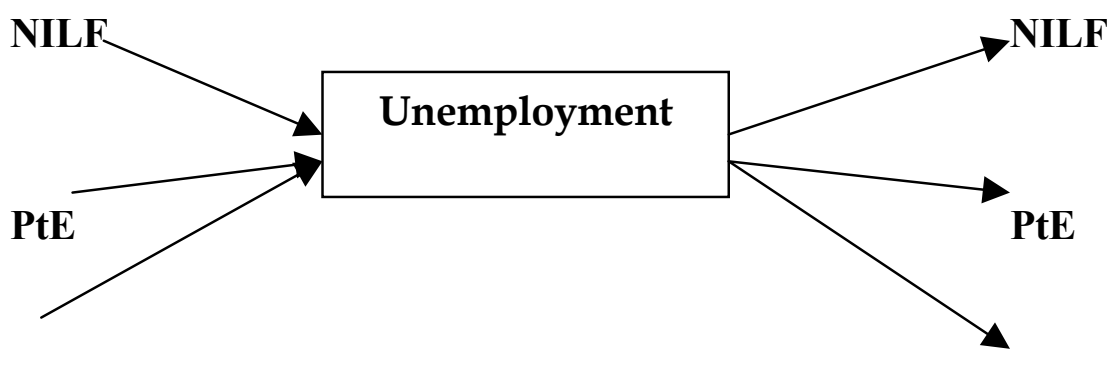

FtE

FtE 


\section{Figure 1b Unemployment spell types}

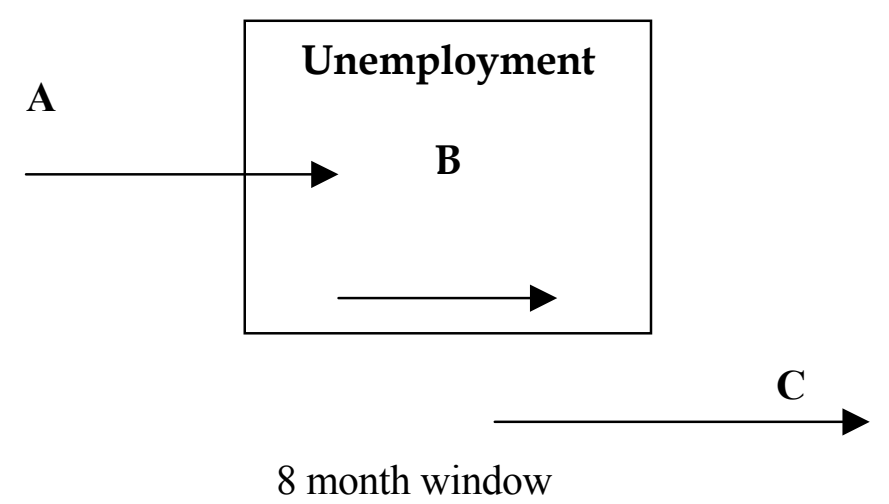

Spells can be left censored (begin before the 8th month- e.g., spell A) or right censored (they do not end by month 8 - e.g., spell C) or be neither left or right censored (they begin and end within the eight month period - e.g., spell B.

Our procedure is to estimate models of unemployment spells that distinguish between three different forms of spell endings; namely, all spell endings (including NILF, FtE and PtE transitions from unemployment), spells ending in employment (FtE and PtE transitions from unemployment) and spells ending in full-time employment. We also add a permutation to this third model in which the individual was employed in the first month of the data window, thereby focusing solely on job loss transitions.

We adopt a hazard model of the following general form

Hazard

$$
\mathrm{H}_{i}=H\left(\eta_{1} O^{*}+\eta_{2} R_{i}+\eta_{3}{ }^{\prime} \boldsymbol{S}_{\boldsymbol{t}}+\boldsymbol{\eta}_{4}{ }^{\prime} \boldsymbol{\theta}_{\boldsymbol{t}}+\eta_{5} \lambda_{i}+\mu_{\mathrm{i}}\right)
$$

where $\mathrm{H}$ is the hazard function, where $O^{*}{ }_{i}$ is predicted/actual homeownership, $R_{i}$ is the predicted replacement ratio, $S$ is a matrix of socio-demographic determinants of unemployment and $\theta_{t}$ is a matrix of quarterly time dummies that account for time-related shocks, $\lambda_{\mathrm{i}}$ is the inverse Mills ratio from the unemployment probit. 
The hazard function gives the probability that an individual leaves a particular state at a particular point in time conditional on being in that state prior to that point. In the present context, the hazard function gives the probability of exiting unemployment at a given point in time, given that individual had been unemployed up to that point. We shall utilize Cox's proportional hazards model, where we model the hazard function using the following functional form:

$$
\mathrm{h}(\mathrm{t}, \mathrm{X})=\mathrm{h}(\mathrm{t}, 0) \exp \left(\mathbf{b}^{\prime} \mathbf{X}\right)
$$

where $\mathrm{h}(\mathrm{t}, 0)$ is the baseline hazard rate. The baseline hazard rate reflects the influence of spell duration on the hazard rate and is independent of the set of determinants. Correspondingly, the second component of the hazard function $\exp \left(\mathbf{b}^{\prime} \mathbf{X}\right)$ is independent of time but is dependent on the set of regression coefficients and the associated $\mathbf{X}$ determinants. The assumed constancy of hazards over time is the basis for the 'proportional hazards' model label.

\section{Housing Tenure and Leverage}

We distinguish between five housing tenure states: (1) outright owners, (2) owners with mortgages, (3) private market renters (the default category in the regressions), (4) public renters and (5) free renters. ${ }^{8}$ The latter category includes young people who still reside with their parents (and are not defined as dependent children) in a rent-free state. We estimate unemployment incidence and unemployment duration models incorporating these differentiated tenure positions. Our models use both actual tenure states as dummy variables and predicted tenure states utilizing the results of a multinomial logit model of tenure choice. The omitted tenure category is the private rental category (tenants paying market rents).

\footnotetext{
${ }^{8}$ We note that the research on public housing fails to compare public housing with homelessness and with charitybased housing. It could be argued that this group, typically absent from major datasets (including our own), is as relevant a comparison tenure for public housing as are private renters and owners.
} 
Just as missing variables threatens to confound the impact of observed ownership on unemployment duration, so, too, with observed public housing. Bover, Muellbauer, and Murphy (1989) point out that public housing typically represents 'housing of last resort'. They suggest that it would be natural to expect that a number of unobservable (in most datasets) characteristics such as low motivation, low ability, bad luck, poor health are likely to be correlated with public housing. This means that part of the regional mobility and unemployment differentials found between housing tenures may be due to unobserved heterogeneity effects as compared to housing tenure effects per se.

We extend the Oswald framework in one last important respect. Among homeowners, we anticipate that the degree of leverage affects labor market behavior. Those with high leverage will typically have greater out of pocket housing costs than private renters occupying an equivalent dwelling, while those with low leverage will have lower costs. ${ }^{9}$ The greater are housing expenses, the greater the pressure on the homeowner to return to work. To test this hypothesis, we repeat the above probability of unemployment and duration of unemployment estimations on homeowners only (and then on owners with mortgages only), using their leverage (and predicted leverage) as an explanatory variable. We expect that the greater the leverage, the greater the probability and/or the duration of unemployment.

\section{The Data}

The dataset used in this study is the Australian Survey of Income and Housing Costs (SIHC) Confidentialised Unit Record Files for the four consecutive years 1994-97 years. Roughly 13,500 persons in private resident dwellings are surveyed in each of the four years leading to a sample of

\footnotetext{
${ }^{9}$ The mortgage rate being paid includes a premium to cover expected inflation. Rents do not need to include such a premium because landlords should expect to receive capital gains to compensate for inflation. In a zero inflation world, out of pocket costs of owners using extreme leverage still need not exceed those of renters.
} 
56,370 individual respondents in the pooled 1994-1997 SIHC. These annual surveys were conducted broadly under the same sampling conditions and in a period of stable economic growth in Australia. We have inflated nominal values in each of the SIHC data sets to their 1997 equivalents using the Consumer Price Index values for Australia in the relevant years.

The sampling frame of the SIHC is all those aged 15 and over living in private residences. Excluded are those people resident in non-private residences (e.g., hotels, boarding schools, boarding houses and institutions), the homeless, those living in remote areas of the Northern Territory, and members of permanent defense forces. We delete from the data all income units whose head is aged 65 and over and dependent children over 15 (full-time students aged 15 to 24 who themselves do not have spouses or dependent children of their own). Just over eight percent of the respondents in the labor force are unemployed.

The SIHC data set is cross-sectional. However, respondents to the SIHC are drawn from Australia's Monthly Population Survey (MPS), which tracks an individual's labor force outcomes during an eight- month window. The MPS labor force data for each individual is linked by the ABS to the rich SIHC questionnaire containing housing-related questions (housing tenure, dwelling structure and location, estimated house value, housing loans and repayments, housing costs, and year of purchase), labor market questions (e.g., wages, labor force position), sociodemographic information (e.g., age, education, country of birth, family type) and detailed income data.

An overview of housing and labor force variables of the SIHC data for our modeling purposes is contained in Tables 1 and 2. Owners comprise 51.2 per cent of income units after taking into account the exclusion of those aged 65 and dependent children. While not displayed in Tables 1 and 2, homeownership rises with age and education level. Around half of owner-occupier income units are outright owners and the other half owners with mortgages. The mean loan-to- 
value ratio for owners with mortgages is 0.43 ; around 12 per cent of owners with mortgages have loan-to-value ratios exceeding 80 percent. Private renters comprise close to one-third of income units in the sample while public renters represent five per cent of all income units. Income units neither owning nor paying rent to a landlord comprise a relatively large 11 per cent of all income units (the rent-free category).

The unemployment rate for female homeowners stands at 3.9 per cent while that for male owners is 4.1 per cent. For both women and men the unemployment rate for owners with mortgages is lower than that for outright owners. In the case of males, the difference is relatively large; outright owners having almost twice the unemployment rate of leveraged owners. Private renters exhibit unemployment rates four times those of homeowners. The unemployment rate for female public renters is twice that of private renters, while for males the ratio of unemployed to employed is closer to three to one. Those in rent-free accommodation exhibit unemployment rates similar to those in the private rental category.

An important economic determinant of unemployment outcomes in our models is the predicted replacement ratio (the ratio of unemployment benefits to earnings). We use actual weekly earnings and benefits to model predicted weekly earnings and benefits and so the predicted replacement ratio. The replacement ratio is imputed to both employed and unemployed persons in our sample. Weekly earnings for women are two-thirds the earnings for men (much of this is a lower hours effect). Because unemployment benefits are roughly equal for women and men, it is not surprising that predicted replacement ratios are higher for women than men. Ratios are also higher for unemployed persons than employed persons. The distributional results presented in Table 2 indicate that the vast majority of persons are predicted to face replacement ratios lower than 0.5 . 


\section{Results}

\section{I. $\quad$ Probability of Unemployment}

We begin with tests of the simple owner-versus-renter hypothesis analogous to tests of Coulson and Fisher (2002) and Hendershott and Green (2002) to determine if the results for Australia are similar to those for the U.S. Table 3 reports separate results for males and females on the effect of homeownership on unemployment after controlling for the range of confounding influences.

Model 1 presents probit model results for the case in which we treat homeownership as an exogenous variable (actual homeownership) while model 2 includes both actual homeownership and the homeownership error term to test for exogeneity in homeownership. Because the error term is significant, homeownership is treated as an endogenous variable and we include predicted homeownership in our final unemployment probit model (Model 3). (The coefficient on predicted homeownership is roughly three times that in model 1.) Our predicted homeownership variable is derived from a tenure choice probit model whose results are reported in Appendix Table 1. These results reveal a positive relationship between homeownership on the one hand and age, (income unit) income, and education on the other hand. Those born outside Australia tend to have lower rates of homeownership (all other things being equal). Couple income units have higher rates of homeownership than singles and homeownership rates rise with the presence of dependent children.

As is evident in Table 3, predicted ownership has a large negative effect on the probability of unemployment for both women and men, indicating that the probability of unemployment falls as the predicted probability of homeownership rises. The same is true, we note in passing, for our model 1 results, which treated homeownership as an exogenous variable. This runs counter to the Oswald thesis. The precise quantitative impact of a particular variable on the probability of unemployment is gauged by utilizing the marginal effect ( $\mathrm{DF} / \mathrm{dx}$ column) estimates, which give the 
impact of a marginal change in the independent variable on the probability of being unemployed. When the variable is a zero-one dummy, the marginal effect is the impact of going from 0 to 1. (All marginal effect calculations are at the means of variables.) For males, the relevant marginal effect on predicted ownership is -0.235 , while for females the relevant marginal effect value is 0.192. In other words, a one percentage point increase in the predicted probability of being a home owner (say from 0.59 to 0.60 ) decreases the probability of a male being unemployed by 0.235 percentage points (i.e., a drop of 0.00235 in the predicted probability of being unemployed; the mean probability is 0.065 or 6.5 per cent). A one percentage point increase in the predicted probability of a female being a home owner decreases the probability of female being unemployed by 0.192 per cent.

To provide some context to these marginal effect values, consider the impact of the predicted replacement ratio on the probability of being unemployed. For males, a one percentage point increase in the ratio of predicted benefits to predicted wages (say from 0.27 to 0.28 ) increases the probability of a male being unemployed by 0.213 percentage points (i.e., an increase of 0.00213 in the predicted probability of being unemployed). This marginal effect is approximately of the same magnitude as that of the predicted probability of homeownership. Hence, homeownership and the replacement ratio have roughly similar economic effects on the probability of unemployment. In the case of women, the replacement ratio marginal effect is less than half that for males though still significant (the marginal effect is 0.095 for women as compared with 0.213 for men). In addition to homeownership and replacement ratio effects, our results show that the probability of being unemployed is related to income unit type effects, geographical location effects and country of birth effects.

In Table 4, we have repeated the above estimations replacing homeownership with the full range of housing tenure states (the omitted tenure category is private renters). The alternative 
endogenous model replaces actual housing tenure states with predicted housing tenure states.

Predictions of the appropriate housing tenure state are based on the results from a multinomial logit model (see Appendix Table 2). An income unit (and, therefore all relevant persons in that income unit) is allocated to that housing tenure state whose predicted probability value from the multinomial logit model is the highest among all the predicted values. So, for example, if the predicted probability for outright ownership was 0.52 and the predicted probabilities for each of the remaining housing tenures were below this value, the income unit would be assigned to the outright ownership tenure category. Before presenting our results we note that on the basis of this allocation method, the two housing tenure categories with the lowest proportion of income units; namely, public renters and the other rental (rent-free) category are even more under-represented in terms of the distribution of predicted tenure states, giving us quite small samples in these two tenures. The housing tenure variables in Table 4 are all dummy variables and so the stated marginal effects refer to the impact on unemployment of the discrete 0 to 1 jump (from private renting to the housing tenure in question).

For males, outright homeownership reduces the probability of unemployment by about half as much as does ownership with a mortgage, although both effects are significant. The marginal effect for male owners with a mortgage is -0.073 . Hence, male owners with mortgages are 7.3 per cent less likely than private renters to be unemployed. In stark contrast, the probability of being unemployed rises sharply for public renters with the stated marginal effect for men being 0.148 . The other rental category (the rent free category) also displays a marginally higher unemployment propensity than private renters.

Similar tenure effects are found among women. Both female outright owners and female owners with mortgages display significantly lower probabilities of being unemployed than private renters. The marginal effect for female owners with a mortgage is -0.066 and -0.051 for female 
outright owners. These estimates are roughly comparable to the male marginal effects although the difference between the two effects is much smaller in the case of females. Female public renters have a significantly higher probability of being unemployed as compared with female private renters, but the public renter effect is much smaller than in the case of men.

Generally our results using predicted housing tenure confirm those found using actual housing tenure states. There is, however, one important difference. We find significant public housing impacts in the case of actual tenure but when we move to predicted public housing we find no significant effect. The under-prediction of public housing together with the relatively small sample of predicted public renters may lie behind this result.

In Table 5 we restrict ourselves to homeowners only and consider the role of leverage by entering the actual and predicted loan-to-value ratio as a continuous variable in models for all homeowners and for owners with a mortgage. Predicted loan-to-value ratios are based on an OLS model including income, age, education, and other socio-demographic variables (see Appendix Table 3). For males, both the actual and predicted loan-to-value ratios have significant negative effects on the probability of unemployment among all homeowners. The marginal effect for men (actual leverage) is -0.013 , which means that a one percentage point increase in the loan-to-value ratio (e.g., from 0.49 to 0.50 ), reduces the probability of being unemployed by 0.013 points. When we move to owners with mortgages alone we find no significant leverage effect. What this suggests is that those holding mortgages behave differently than those without mortgages controlling for observable forces but that when one mortgagee is compared to another, those men with higher leverage ratios do not exhibit a lower probability of unemployment. There is only one significant leverage effect in the case of women: actual leverage among female mortgagees is opposite to that for men and counter to the arguments on leverage we have presented. Higher actual leverage increases the probability of unemployment. 


\section{The Duration of Unemployment}

We have defined the completion of a spell of unemployment in three different ways with the exit to full-time employment the most stringent and meaningful definition of a spell ending. For this latter spell ending type we also undertake an additional analysis where we restrict spells to workers who we know were employed at the beginning of the 8 -month window. While this definition of a spell limits spells to workers whom we know lost jobs in the relevant period, it comes at some cost as it squeezes the maximum dimensions of the data window (by one month) over which we can view the progress of the spell. It also reduces the number of potential spells.

We begin with a descriptive picture of spell duration by presenting unemployment spell survival curves by housing tenure type for males and females. The survival curve plots the cumulative proportion of those who remain in unemployment (i.e., they 'survive' in the state of unemployment) at different monthly points. The first set of survival curves presented in figure 2 (figures 2a to $2 \mathrm{f}$ ) refer to spells that have no restriction placed on them in terms of when the spell begins but are distinguished according to each of the three spell ending types (NILF + employment, employment, and full-time employment). The final set of survival curves (figures $2 \mathrm{~g}$ and $2 \mathrm{~h}$ ), refer to unemployment spells of job losers.

There are three striking features of the survival curves presented in figure 2 . The first is the steepness of the survival curve in the first two or so months of the 8-month window. This early steepness indicates that most spells of unemployment end quickly. ${ }^{10}$ After a short period, the hazard rate drops off rapidly and so the cumulative survival curve flattens out. The second striking feature is the prominent role played by housing tenure. At one end of the survival curve spectrum lie the survival curves for owners with a mortgage, which typically reveal more rapid early exit

\footnotetext{
${ }^{10}$ The caveat here is that figures $2 \mathrm{a}$ to $2 \mathrm{~g}$ include left censored spells and so the rapid decline includes unemployment spells beginning before the data window ending in the first month as well as fresh spells beginning in the data window ending rapidly.
} 
from the unemployment spell than the other housing tenures. At the other end of the spectrum lie the survival curves for public renters, which almost always reveal relatively slow exit from unemployment. In between these two boundaries typically lie the survival curves of the remaining three tenure categories: owners without mortgages, private renters and the other tenure (rent-free) category.

The third key feature of the survival curves displayed in figure 2 is the shift as we move between the various definitions of when an unemployment spell ends and when a spell begins, with these shifts displaying a strong gender connection. For instance, when we utilize the broadest definition of an unemployment spell end, that of any exit from unemployment, the cumulative survival curve for women is very steep suggesting rapid exit from unemployment. But, relative to men, the survival curves for women become relatively flat as we move to stricter employmentrelated definitions of spell endings. Why the difference? Because women, much more than men, make the unemployment to out of the labor force transition and this transition is ignored in the case of the employment-related spell ending types. (We ignore the transition to the NILF category in the employment-related definitions of a spell exit so that the spell of unemployment continues until an employment-related transit occurs.)

Moreover, for men, the largest gap between the survival curves for owners with mortgages and public renters occurs in the case of exit to full-time employment (refer to figures 2e and $2 \mathrm{~g}$ ). This pattern does not hold for women. Women in the private rental and other rental categories display more rapid exit from unemployment (to full-time employment) than owners with mortgages (see figures $2 \mathrm{f}$ and $2 \mathrm{~h}$ ). This is evidence in favor of the Oswald thesis.

The survival curves displayed in figures $2 \mathrm{a}$ to $2 \mathrm{~h}$ do not control for confounding factors. We, therefore, move to formal modeling of unemployment spells. Our results are presented in Tables 4 and 5 with the sequencing of models following that of the unemployment probits. For 
space reasons, we only report the estimated coefficients of the key variables of interest (housing variables and the replacement ratio) and include hazard ratios for ready interpretation. For continuous variables, the hazard ratio gives the percentage increase (if the ratio is greater than one; decrease if less than one) in the hazard rate for a unit increase in the covariate. If the variable is dichotomous, the hazard ratio gives the risk of exit relative to the default. A hazard ratio greater than one indicates that unemployed people with the designated characteristic exit the unemployment state more quickly than the indicated alternative state. If the hazard ratio is less than one, unemployed people with the given characteristic have a greater chance of 'survival' in unemployment than the default category with the degree of lower risk given by the hazard ratio value.

Table 6 presents hazard model estimates of the impact of homeownership and the predicted replacement ratio on the spell of unemployment. ${ }^{11}$ The 'risk' of a female homeowner exiting the unemployment spell into employment is insignificantly different from that for female nonhomeowners (see Model B, C and D results in Table 6). Notice, however, in terms of the Model A results, that the risk of a female homeowner exiting an unemployment spell altogether, regardless of the type of exit specified, is significantly higher than that of the non-homeowner; female homeowners have a 12.9 per cent higher risk. That is, female homeowners have a higher propensity to exit the labor force during a spell of unemployment than do female non-homeowners, confirming the relationship evident in the survival curves.

The 'risk' of a male homeowner undertaking the transition to full-time employment is significantly higher than for male non-homeowners (see Table 6 Model C). The hazard ratio for men for this model is 1.222 , which means that male homeowners have a 22.2 percent higher 'risk'

\footnotetext{
${ }^{11}$ In the duration analysis, we restrict attention to models using actual homeownership, actual housing tenure and actual leverage given space limitations and focus on the impact of the different spell endings. We note, however, that in preliminary analyses (not reported), we included both actual homeownership and the homeownership error term in our Table 6 hazard models but found that the home ownership error term was insignificant across the various models.
} 
of exiting unemployment within the eight-month window than do male renters (of all rental types); a result that strongly contradicts the Oswald thesis. One interesting feature of the results from other models presented in Table 6 is the fall in the male homeowner relative risk of exiting unemployment as a less strict definition of a spell end is utilized. In the case of a definition of a spell ending when a male unemployed person obtains full-time employment, the relative risk for males is 1.222 while for more inclusive exits the relative risk drops below 1.13 . We attempted to estimate a hazard model on the basis of job loser spells and a full-time employment exit definition of a spell but that model did not produce meaningful results.

Table 7 reports hazard model results utilizing all five housing tenure categories and, for homeowners, the loan-to-value ratio. These results are analogous to those in Tables 4 and 5. The same basic models are estimated, with outright owner, an owner with a mortgage, public housing, and other (rent-free) tenure categories (private renting is the dropped category) in the housing tenure models and the loan-to-value ratio as a continuous variable in a model restricted to homeowners.

As can be seen from the Table 7 Model $\mathrm{C}$ results for men, public renters are likely to exit employment far less rapidly than private renters (hazard ratio of $0.515-48.5$ per cent lower risk). On the other hand, owners with mortgages are likely to exit unemployment to employment and especially to full-time employment far more quickly than are private renters (hazard ratios of 1.199 and 1.444). There is no significant impact for outright owners (no Oswald effect).

To test the role of leverage in influencing the exit from unemployment behavior of homeowners we restrict the sample to homeowners and include the loan-to-value ratio as an explanatory variable (the LVR sub-model in Table 7). We find that an increase in the loan-to-value ratio significantly increases the 'risk' of an exit from unemployment to employment and especially full-time employment for male homeowners. We conjecture that these results are due to the 
potential loss of one's own home owing to an inability to make mortgage payments while unemployed.

The effects are weakened considerably when we move to the most inclusive exit (Model A), including exit to out of the labor force. When we move to the restricted model of job loser spells of unemployment (Model D) the results on male public renters and outright owners remain. While the coefficient on the owner with mortgage variable is not significant, the loan-to-value ratio exerts its strong effect on increasing the hazard of exit from unemployment among homeowners.

Turning to the case of unemployment spells among women, we find that female private renters and owners with mortgages are indistinguishable in terms of the full-employment exit hazard model results (Model C). However, both female outright owners (hazard ratio 0.586) and public owners (hazard ratio 0.575 ) have a sharply lower risk of exit from unemployment than the private rental group. The Oswald effect holds with a vengeance for outright female owners. This effect carries through to the more stringent Model D results, which restrict the sample of unemployment spells to job loser spells, but the public renter effect does not. Finally, a higher replacement ratio significantly slows female exits to full time unemployment. ${ }^{12}$

\section{Summary}

This paper represents another test of the Oswald hypothesis that higher homeownership causes higher unemployment. The key explanation offered by Oswald for this outcome is that homeowners who lose their job face high housing-related transaction costs if they take the option of moving to another region to obtain employment. There is obvious truth in this. However, it is also true that a range of housing-related channels link housing and labor markets. One of these is that homeowners with large mortgages might be more willing to accept wage cuts and/or ratchet up work effort (productivity) in order to remain employed or to

\footnotetext{
${ }^{12}$ Male exits are slowed, but not significantly. However, the coefficient is significant for the homeowners-only model.
} 
exit unemployment quicker than renters (or owners without large mortgages) because of the requirement to meet mortgage repayments to save their house. This housing-labor link suggests that we should expect significant differences within the homeowner group in terms of labor market behavior.

Likewise, Oswald's thesis ignores the role of public housing and rent-free housing. Public renters and rent-free 'renters' may be 'locked in' to their present abodes and face high costs of their own (but of a different nature to those experienced by homeowners) if they consider accepting a job offer particularly when it involves a move to another locality. Transaction costs are not the key driver as in the case of homeowners; rather the key to the poor labor market outcome is the potential loss of secure low-rent tenancies that are, in the main, location-specific. What this implies is that unless account is taken of homeowner leverage and multiple rental categories, we are unlikely to obtain an accurate and comprehensive overview of how housing affects the labor market.

Our analysis of the probability of being unemployed and of the duration of unemployment spells is based on the pooling of four consecutive annual surveys of the SIHC during the mid-1990s all conducted broadly under the same sampling conditions and in a period of stable economic growth in Australia. In the duration analysis we distinguish carefully between the labor force states that a person may exit to (the competing risks they face). We therefore, distinguish between an exit from unemployment to employment (and then make the further part-time versus full-time employment distinction) and from unemployment to out of the labor force.

A variety of estimations are performed. In terms of the probability of being unemployed, in no case do we find evidence in support of the Oswald hypothesis that owners have worse employment outcomes that private renters, and in most cases we find evidence of the opposite - higher homeownership causes lower unemployment. Further, owners have significantly quicker exits from unemployment than do private renters, male to full time employment and females out of the labor force. More importantly, however, we show that the key to the counter Oswald results for males is that owners with mortgages display the lower probability of being unemployed and experience higher relative risks of exit from a spell of unemployment. 
In fact, outright owners, especially females, have significantly slower exits from unemployment, especially to full time employment. This is the only support we find for the Oswald hypothesis.

Just as the degree of leverage affects homeowners' probability of becoming unemployed and their duration if unemployed, the type of renter status affects renters' probabilities and durations. Both public housing tenants and those living rent-free are more likely than private renters to become unemployed, and public renters who become unemployed have longer durations than do private or rent-free renters.

Finally, our results indicate a significant impact of the predicted replacement ratio (unemployment benefits to wage if reemployed) on unemployment behavior. Persons with a higher predicted ratio are significantly more likely to become unemployed and unemployed females with higher predicted ratio have longer unemployment spells than do those with lower predicted ratios. Unemployed males with high replacement ratios have longer unemployment spells but significantly so only in the homeowners-only model. 


\section{References}

Archer, W.R., Ling, D.C., and McGill, G.A. (1996), The Effect of Income and Collateral

Constraints on Residential Mortgage Terminations, Regional Science and Urban Economics, 26, $235-261$.

Australian Bureau of Statistics (ABS), (1999), 1997-98 Survey of Income and Housing Costs, Australia, Confidentialised Unit Record File (CURF), Technical Paper, Catalogue Number 6541.0.30.001, ABS, Canberra.

Bover, O. and Muellbauer, J. and Murphy, A. (1989), Housing, Wages and UK Labour Markets, Oxford Bulletin of Economics and Statistics, 51, 97-136.

Caplin, A.C., Freeman, C., and Tracy, J. (1997), Collateral Damage: Refinancing Constraints and Regional Recessions, Journal of Money, Credit, and Banking, 29, 496-516.

Coulson, N.E. and Fisher, N. M. (2002), Tenure Choice and Labor Market Outcomes, Housing Studies, 17, 35-49.

Engleman, S.R. (1977), The move into council housing: The effect on quit rates, Urban Studies, 14, 161-168.

Gardner, J., Pierre, G., and Oswald, A.J. (2001), Moving for a reason, mimeo, Warwick University.

Goss, E.P. and Phillips, J.M. (1997), The Impact of Home Ownership on the Duration of Unemployment, Review of Regional Studies, 27, 9-27.

Green, R.K. and Hendershott, P.H. (2001), Homeownership and Unemployment in the US, Urban Studies, 38, 1509-1520.

Green, R.K. and Hendershott, P.H. (2002), Homeownership and the Duration of Unemployment: A Test of the Oswald Hypothesis, paper presented at AREUEA Annual Meetings, January 2002.

Hendershott, P.H. and Hu, S. (1982), Accelerating Inflation, Nonassumable Fixed Rate Mortgages, and Consumer Choice and Welfare, Public Finance Quarterly, 158-184.

Henley, A. (1998), Residential Mobility, Housing Equity and the Labour Market, The Economic Journal, 108, 414-427.

Hughes, G.A. and McCormick, B. (1981), Do Council Housing Policies Reduce Migration between regions?, Economic Journal, 91, 919-937. 
Hughes, G.A. and McCormick, B. (1985), Migration Intentions in the UK: Which Households Want to Migrate and which Succeed?, Economic Journal, 95, Conference Supplement, 76-95.

Hughes, G.A. and McCormick, B. (1987), Housing Markets, Unemployment and Labour market Flexibility in the UK, European Economic Review, 31, 615-641.

McCormick, B. (1983), Housing and Unemployment in Great Britain, Oxford Economic Papers, 35, 283-305.

Minford, P., Ashton, P. and Peel, M. (1988), The Effects of Housing Distortions on Unemployment, Oxford Economic Papers, 40, 322-345.

Nickell, S. (1998), Unemployment: Questions and Some Answers, Economic Journal, 108, 802816.

Nickell, S. and Layard (1999), Labor Market Institutions and Economic Performance, in Ashenfelter, Orley and Card, David, (eds.) Handbook of Labor Economics, Volume 3C, Handbooks in Economics, vol. 5, Amsterdam; New York and Oxford: Elsevier Science, NorthHolland, 3029-84.

Oswald, A.J. (1996), A Conjecture on the Explanation for High Unemployment in the Industrialised Nations: Part I, mimeo, Warwick University.

Oswald, A.J. (1997), Theory of Homes and Jobs, mimeo, Warwick University.

Partridge, M.D. and Rickman, D.S. (1997), The Dispersion of US State Unemployment Rates: The Role of Market and Non-market Equilibrium Factors, Regional Studies, 31, 593-606.

Pehkonen, J. (1997), Unemployment and Homeownership, Applied Economic Letters, 6, 263265.

Quigley, J. (1987), Interest Rate Variation, Mortgage Prepayments, and Household Mobility, Review of Economics and Statistics, 49, 636-643.

Van Leuvensteijn, M., and Koning, P. (2000), The Effects of Homeownership on Labor Mobility in the Netherlands: Oswald's Theses Revisited, Research Memorandum No. 173, CPB Netherlands Bureau for Economic Policy Analysis, The Hague. 


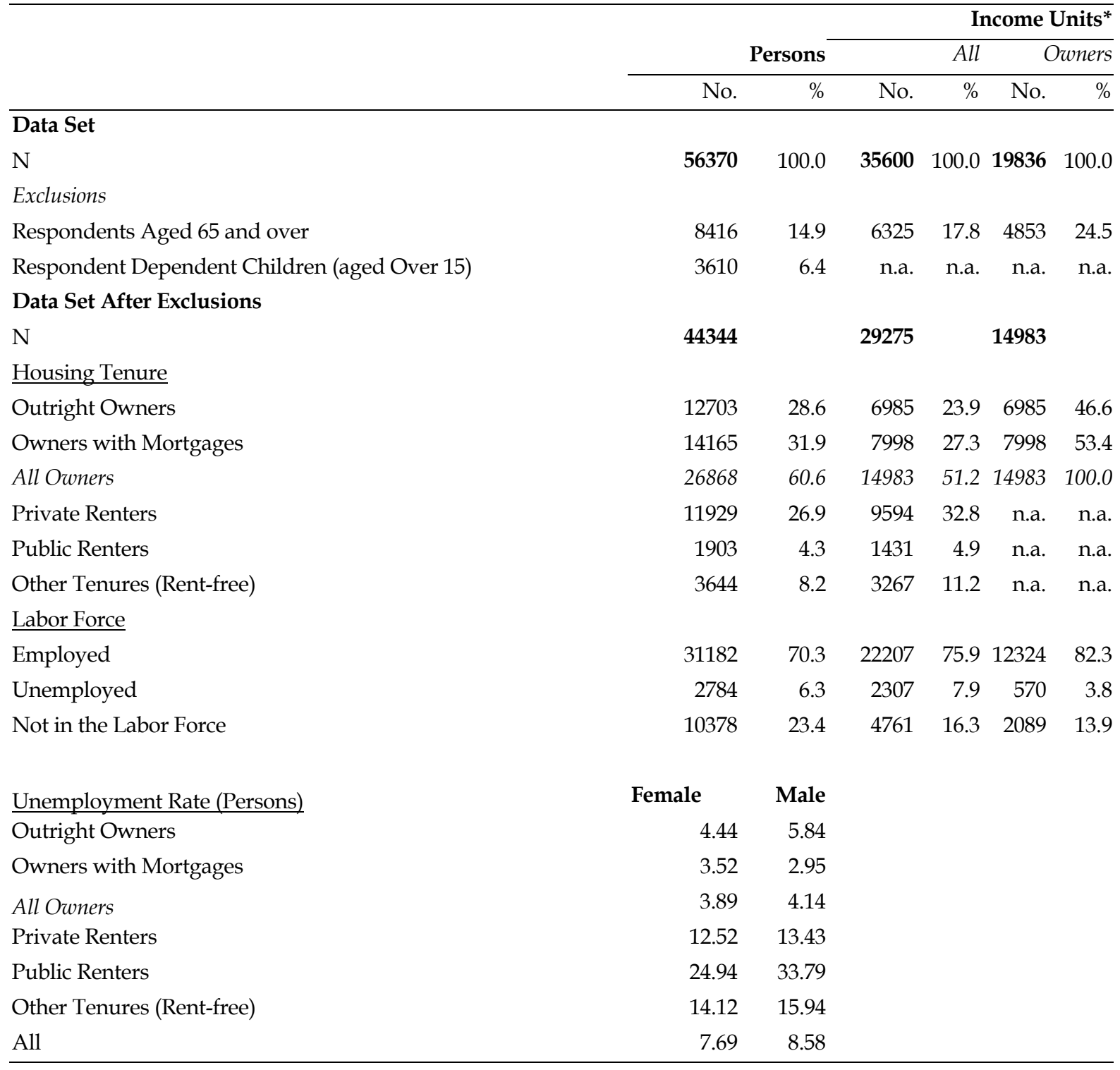


Table 2 The Distribution of Loan-to-Value Ratios, Real Weekly Earnings, Real Weekly Unemployment Benefits, and the Predicted Replacement Ratio, 1993-94 to 1996-97 SIHC.

\begin{tabular}{lcccc}
\hline & & 10th & 50th & 90th \\
& Mean Percentile Percentile & Percentile \\
\hline Owners with mortgages (income units) & 0.44 & 0.06 & 0.41 & 0.83 \\
Loan-to-value ratio & & & & \\
Females & 477 & 325 & 454 & 678 \\
Actual weekly wages (employed) \$ & 130 & 56 & 127 & 216 \\
Actual weekly unemployed benefits (unemployed) \$ & 0.27 & 0.14 & 0.25 & 0.42 \\
Predicted replacement ratio (employed) & 0.33 & 0.14 & 0.30 & 0.56 \\
Predicted replacement ratio (unemployed) & & & & \\
Males & & & & \\
Actual weekly wages (employed) \$ & 720 & 472 & 705 & 996 \\
Actual weekly unemployed benefits (unemployed) \$ & 124 & 53 & 454 & 166 \\
Predicted replacement ratio (employed) & 0.18 & 0.10 & 0.17 & 0.28 \\
Predicted replacement ratio (unemployed) & 0.23 & 0.14 & 0.23 & 0.31 \\
\hline
\end{tabular}


Table 3 Probit Model: Probability of Being Unemployed, Males and Females, 1993-94 to 1996-97 SIHC

\begin{tabular}{|c|c|c|c|c|c|c|c|c|c|c|c|c|c|c|}
\hline & \multicolumn{7}{|l|}{ Males } & \multicolumn{7}{|l|}{ Females } \\
\hline & \multicolumn{2}{|l|}{ Model 1} & \multicolumn{2}{|l|}{ Model 2} & \multicolumn{2}{|l|}{ Model 3} & \multicolumn{3}{|c|}{ Model 1} & \multicolumn{2}{|l|}{ Model 2} & \multicolumn{3}{|l|}{ Model 3} \\
\hline & Coef. & Sig. & Coef. & Sig. & Coef. & Sig. & $\mathrm{DF} / \mathrm{dx}$ & Coef. & Sig. & Coef. & Sig. & Coef. & Sig. & $\overline{\mathrm{DF} / \mathrm{dx}}$ \\
\hline Constant & -1.696 & 0.000 & -1.458 & 0.000 & -1.473 & 0.000 & & -1.456 & 0.000 & -1.335 & 0.000 & -1.505 & 0.000 & \\
\hline Homeowner & -0.611 & 0.000 & -1.844 & 0.000 & & & & -0.631 & 0.000 & -1.778 & 0.000 & & & \\
\hline Predicted homeowner & & & & & -1.842 & 0.000 & -0.235 & & & & & -1.673 & 0.000 & -0.192 \\
\hline Homeownership error term & & & 1.448 & 0.000 & & & & & & 1.343 & 0.000 & & & \\
\hline Predicted replacement ratio & 2.200 & 0.000 & 1.571 & 0.000 & 1.675 & 0.000 & 0.213 & 0.887 & 0.000 & 0.797 & 0.000 & 0.828 & 0.000 & 0.095 \\
\hline Couple & 0.030 & 0.856 & 0.515 & 0.003 & 0.521 & 0.003 & 0.059 & -0.334 & 0.124 & 0.002 & 0.993 & -0.093 & 0.670 & -0.011 \\
\hline Sole parent & -0.187 & 0.178 & -0.076 & 0.591 & -0.099 & 0.482 & -0.012 & -0.040 & 0.610 & -0.106 & 0.187 & -0.123 & 0.122 & -0.013 \\
\hline Married or defacto & 0.023 & 0.891 & 0.245 & 0.159 & 0.259 & 0.138 & 0.031 & 0.210 & 0.332 & 0.539 & 0.015 & 0.568 & 0.009 & 0.059 \\
\hline Separated, widowed, divorced & 0.077 & 0.174 & 0.489 & 0.000 & 0.506 & 0.000 & 0.089 & 0.161 & 0.005 & 0.551 & 0.000 & 0.508 & 0.000 & 0.079 \\
\hline No. of dep. children in the income unit & 0.008 & 0.739 & 0.074 & 0.002 & 0.075 & 0.002 & 0.010 & -0.045 & 0.135 & 0.017 & 0.583 & 0.015 & 0.634 & 0.002 \\
\hline Youngest child less than 1 year old & -0.132 & 0.123 & -0.359 & 0.000 & -0.357 & 0.000 & -0.035 & 0.381 & 0.001 & 0.216 & 0.066 & 0.203 & 0.080 & 0.027 \\
\hline Youngest child 1 year old & -0.005 & 0.953 & -0.242 & 0.005 & -0.258 & 0.003 & -0.027 & 0.068 & 0.533 & -0.085 & 0.450 & -0.089 & 0.419 & -0.010 \\
\hline Youngest child 2 years old & -0.136 & 0.145 & -0.339 & 0.000 & -0.346 & 0.000 & -0.034 & -0.010 & 0.930 & -0.134 & 0.258 & -0.115 & 0.322 & -0.012 \\
\hline Youngest child 3 years old & -0.119 & 0.261 & -0.269 & 0.013 & -0.256 & 0.016 & -0.027 & 0.206 & 0.073 & 0.117 & 0.317 & 0.136 & 0.236 & 0.017 \\
\hline Youngest child 4 years old & -0.207 & 0.075 & -0.368 & 0.002 & -0.372 & 0.002 & -0.036 & 0.134 & 0.258 & 0.046 & 0.701 & 0.043 & 0.721 & 0.005 \\
\hline Youngest child 5 years old & -0.176 & 0.128 & -0.304 & 0.010 & -0.316 & 0.007 & -0.032 & 0.182 & 0.137 & 0.109 & 0.380 & 0.129 & 0.291 & 0.016 \\
\hline Youngest child 6 to 9 years old & -0.178 & 0.031 & -0.284 & 0.001 & -0.277 & 0.001 & -0.029 & 0.181 & 0.029 & 0.149 & 0.078 & 0.153 & 0.069 & 0.019 \\
\hline Youngest child 10 or older & -0.045 & 0.530 & -0.071 & 0.325 & -0.069 & 0.338 & -0.008 & 0.069 & 0.377 & 0.094 & 0.236 & 0.095 & 0.228 & 0.012 \\
\hline Sydney & -0.070 & 0.305 & -0.079 & 0.251 & -0.078 & 0.259 & -0.009 & -0.079 & 0.314 & -0.068 & 0.395 & -0.062 & 0.433 & -0.007 \\
\hline Country NSW & 0.276 & 0.000 & 0.344 & 0.000 & 0.339 & 0.000 & 0.053 & 0.222 & 0.010 & 0.264 & 0.003 & 0.258 & 0.003 & 0.035 \\
\hline Melbourne & 0.145 & 0.025 & 0.232 & 0.000 & 0.228 & 0.000 & 0.033 & 0.133 & 0.076 & 0.216 & 0.005 & 0.201 & 0.008 & 0.026 \\
\hline Country Victoria & 0.188 & 0.018 & 0.312 & 0.000 & 0.303 & 0.000 & 0.047 & 0.086 & 0.388 & 0.176 & 0.081 & 0.158 & 0.115 & 0.020 \\
\hline Brisbane & 0.032 & 0.662 & 0.069 & 0.363 & 0.064 & 0.389 & 0.009 & 0.012 & 0.889 & 0.037 & 0.671 & 0.025 & 0.770 & 0.003 \\
\hline Country Queensland & 0.240 & 0.001 & 0.284 & 0.000 & 0.279 & 0.000 & 0.042 & 0.230 & 0.006 & 0.254 & 0.003 & 0.247 & 0.003 & 0.033 \\
\hline Adelaide & 0.276 & 0.000 & 0.357 & 0.000 & 0.343 & 0.000 & 0.054 & 0.181 & 0.030 & 0.251 & 0.003 & 0.237 & 0.005 & 0.032 \\
\hline
\end{tabular}


Table 3 Probit Model: Probability of Being Unemployed, Males and Females, 1993-94 to 1996-97 SIHC

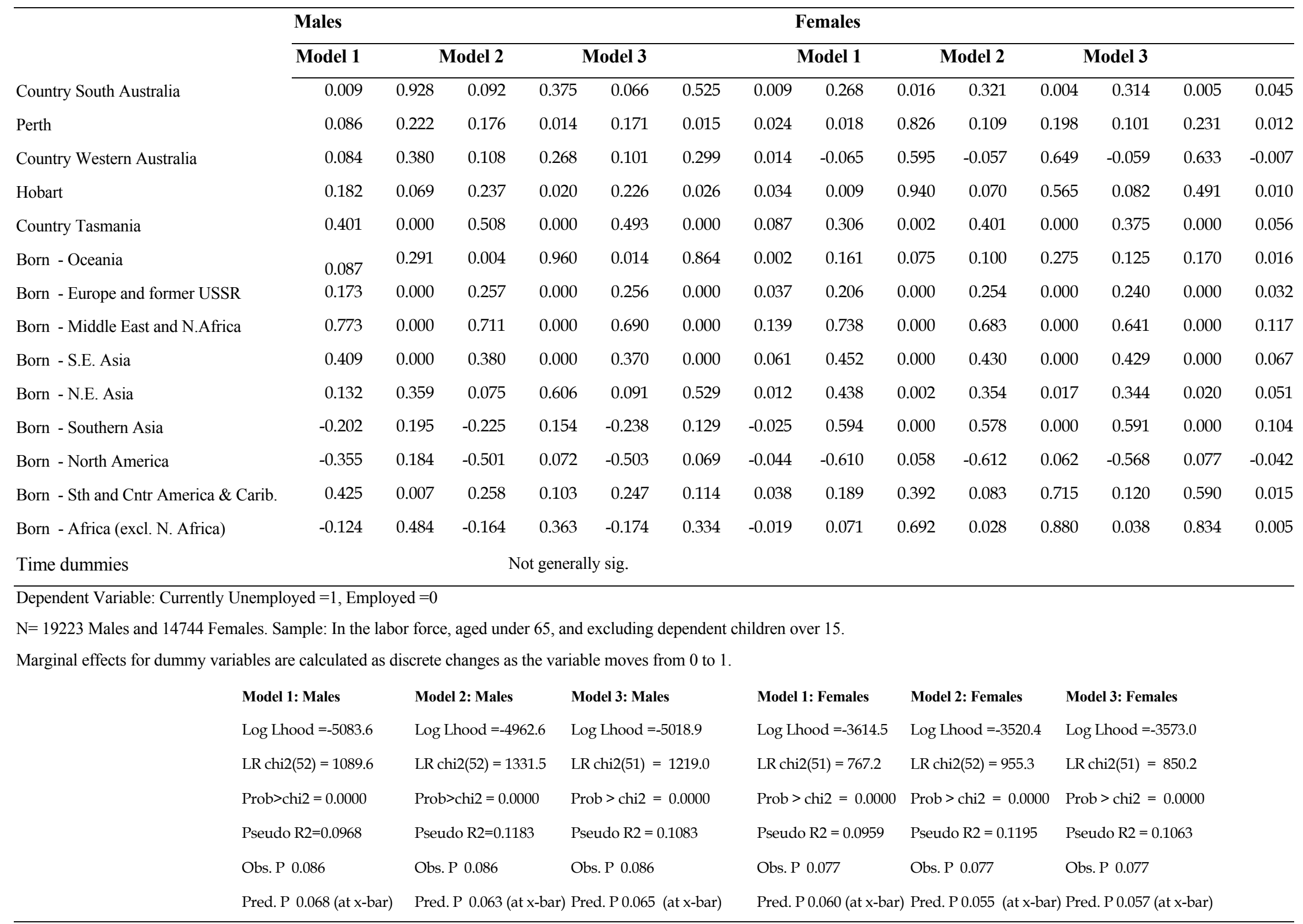


Table 4 Probit Model: Probability of Being Unemployed, Males and Females, Tenure Effects, 1993-94 to 1996-97 SIHC

\begin{tabular}{|c|c|c|c|c|c|c|c|c|c|c|c|c|}
\hline & Males & & & & & & Females & & & & & \\
\hline & Model 1 & & & Model 3 & & & Model 1 & & & Model 3 & & \\
\hline & Coef. & Sig. & $\mathrm{DF} / \mathrm{dx}$ & Coef. & Sig. & $\mathrm{DF} / \mathrm{dx}$ & Coef. & Sig. & $\mathrm{DF} / \mathrm{dx}$ & Coef. & Sig. & $\overline{\mathrm{DF} / \mathrm{dx}}$ \\
\hline Constant & -1.592 & 0.000 & & -1.612 & 0.000 & & -1.487 & 0.000 & & -1.688 & 0.000 & \\
\hline Outright owner & -0.371 & 0.000 & -0.041 & & & & -0.522 & 0.000 & -0.051 & & & \\
\hline Owner with a mortgage & -0.656 & 0.000 & -0.073 & & & & -0.624 & 0.000 & -0.066 & & & \\
\hline Public renter & 0.728 & 0.000 & 0.148 & & & & 0.336 & 0.000 & 0.050 & & & \\
\hline Other renter & 0.042 & 0.340 & 0.005 & & & & 0.074 & 0.164 & 0.009 & & & \\
\hline Predicted replacement ratio & 1.592 & 0.000 & 0.202 & & & & 0.738 & 0.000 & 0.087 & & & \\
\hline Predicted outright owner & & & & -0.394 & 0.000 & -0.045 & & & & -0.461 & 0.000 & -0.048 \\
\hline Predicted owner with a mortgage & & & & -0.826 & 0.000 & -0.101 & & & & -0.615 & 0.000 & -0.071 \\
\hline Predicted public renter & & & & 0.130 & 0.432 & 0.019 & & & & 0.166 & 0.133 & 0.023 \\
\hline Predicted other renter & & & & 0.342 & 0.000 & 0.057 & & & & 0.680 & 0.000 & 0.132 \\
\hline Predicted replacement ratio & & & & 1.778 & 0.000 & 0.233 & & & & 0.896 & 0.000 & 0.110 \\
\hline Other controls (see Table 3) & & & & & & & & & & & & \\
\hline Dependent Variable: Currently Un & $=1$, Employed $=$ & & & & & & & & & & & \\
\hline$N=19,223$ Males and 14,744 Fen & le: In the labor & orce, aged & d under 6 & 65 , homeowner & and exclu & uding dep & pendent childre & n over 15 & & & & \\
\hline Marginal effects for dummy varia & ulated as discre & te changes & $\mathrm{s}$ as the $\mathrm{v}$ & variable moves & from 0 to & & & & & & & \\
\hline & Model 1: Mal & & & Model 3: Malc & & & Model 1: Fem & ales & & Model 3: Fe & nales & \\
\hline & Log likelihoo & $d=-5011.3$ & & Log likelihoo & $d=-5113.3$ & & Log likelihoo & $d=-3603.1$ & & Log likelihc & $\mathrm{d}=-3653.9$ & \\
\hline & LR chi2 $(54)=$ & 1234.09 & & LR chi2 $(54)=$ & $=1030.1$ & & LR chi2(54) = & 789.88 & & LR chi2(54) & $=688.23$ & \\
\hline & Prob $>$ chi $2=$ & 0.0000 & & Prob $>$ chi $2=$ & $=0.0000$ & & Prob $>$ chi $2=$ & 0.0000 & & Prob > chi2 & $=0.0000$ & \\
\hline & Pseudo R2 $=0$ & 1096 & & Pseudo R2 $=0$ & .0915 & & Pseudo R2 = & 0.099 & & Pseudo R2 & 0.086 & \\
\hline & Obs. P 0.086 & & & Obs. P 0.086 & & & Obs. P 0.077 & & & Obs. P 0.07 & & \\
\hline & Pred. P 0.065 & (at x-bar) & & Pred. P 0.068 & (at $x$-bar) & & Pred. P 0.059 & (at x-bar) & & Pred. P 0.06 & (at x-bar) & \\
\hline
\end{tabular}


Table 5 Probit Model: Probability of Being Unemployed, Leverage of Homeowners, Males and Females, 1993-94 to 1996-97 SIHC

\begin{tabular}{|c|c|c|c|c|c|c|c|c|c|c|c|c|}
\hline & \multicolumn{6}{|c|}{ Males } & \multicolumn{6}{|l|}{ Females } \\
\hline & \multicolumn{2}{|c|}{ All Homeowners } & \multicolumn{4}{|c|}{ Owners with a mortgage } & \multicolumn{2}{|c|}{ All Homeowners } & \multicolumn{4}{|c|}{ Owners with a mortgage } \\
\hline & Coef. & Sig. & $\mathrm{DF} / \mathrm{dx}$ & Coef. & Sig. & $\mathrm{DF} / \mathrm{dx}$ & Coef. & Sig. & $\mathrm{DF} / \mathrm{dx}$ & Coef. & Sig. & $\mathrm{DF} / \mathrm{dx}$ \\
\hline \multicolumn{13}{|l|}{ Model 1} \\
\hline Constant & -2.845 & 0.000 & & -3.214 & 0.000 & & -2.683 & 0.000 & & -3.028 & 0.000 & \\
\hline Loan-to-value ratio & -0.175 & 0.034 & -0.013 & 0.095 & 0.423 & 0.005 & 0.058 & 0.509 & 0.004 & 0.262 & 0.040 & 0.016 \\
\hline Predicted replacement ratio & 4.735 & 0.000 & 0.352 & 5.352 & 0.000 & 0.290 & 1.468 & 0.000 & 0.105 & 1.450 & 0.000 & 0.090 \\
\hline \multicolumn{13}{|l|}{ Other controls (see Table 3) } \\
\hline \multicolumn{13}{|l|}{ Model 3} \\
\hline Constant & -2.510 & 0.000 & & -2.968 & 0.000 & & -2.337 & 0.000 & & -2.879 & 0.000 & \\
\hline Predicted loan-to-value ratio & -0.933 & 0.000 & -0.068 & -0.314 & 0.313 & -0.017 & -0.224 & 0.266 & -0.016 & -0.012 & 0.972 & -0.001 \\
\hline Predicted replacement ratio & 4.614 & 0.000 & 0.336 & 5.340 & 0.000 & 0.288 & 1.379 & 0.000 & 0.098 & 1.422 & 0.001 & 0.089 \\
\hline Other controls (see Table 3) & & & & & & & & & & & & \\
\hline
\end{tabular}

Dependent Variable: Currently Unemployed $=1$, Employed $=0$

$\mathrm{N}($ Homeowners $)=11,448$ Males and 9,008 Females. $\mathrm{N}($ Owners with a mortgage $)=6,722$ Males and 5,233 Females.

Sample: In the labor force, aged under 65, homeowner and excluding dependent children over 15.

Marginal effects for dummy variables are calculated as discrete changes as the variable moves from 0 to 1 .

\begin{tabular}{|c|c|c|c|}
\hline All Homeowners & Owners with a mortgage & All Homeowners & Owners with a mortgage \\
\hline Model 1: Males & Model 1: Males & Model 1: Females & Model 1: Females \\
\hline Log likelihood =-1843.8 & Log likelihood =-828.4 & Log likelihood =-1389.3 & Log likelihood =-735.8 \\
\hline LR chi2(50) $=252.14$ & LR chi2 $(50)=129.1$ & LR chi2(49) = 199.96 & LR chi2(47) = 148.24 \\
\hline Prob $>$ chi $2=0.0000$ & Prob $>$ chi $2=0.0000$ & Prob $>$ chi $2=0.0000$ & Prob $>$ chi $2=0.0000$ \\
\hline Pseudo R2 =0.064 & Pseudo R2 =0.0723 & Pseudo R2 = 0.067 & Pseudo R2 = 0.0915 \\
\hline Obs. P 0.041 & Obs. P 0.029 & Obs. P 0.039 & Obs. P 0.036 \\
\hline Pred. P 0.033 (at x-bar) & Pred. P 0.023 (at x-bar) & Pred. P 0.032 (at x-bar) & Pred. P 0.027 (at x-bar) \\
\hline All Homeowners & Owners with a mortgage & All Homeowners & Owners with a mortgage \\
\hline Model 3: Males & Model 3: Males & Model 3: Females & Model 3: Females \\
\hline Log likelihood =-1834.0 & Log likelihood =-828.3 & Log likelihood =-1389.13 & Log likelihood =-737.9 \\
\hline LR chi2 $(50)=278.78$ & LR chi2 $(50)=129.5$ & LR chi2(49) = 200.74 & LR chi2(47) $=144.07$ \\
\hline Prob $>$ chi $2=0.0000$ & Prob $>$ chi $2=0.0000$ & Prob $>$ chi $2=0.0000$ & Prob $>$ chi $2=0.0000$ \\
\hline Pseudo R2 =0.0706 & Pseudo R2 =0.0725 & Pseudo R2 = 0.067 & Pseudo R2 = 0.0889 \\
\hline Obs. P 0.041 & Obs. P 0.029 & Obs. P 0.039 & Obs. P 0.036 \\
\hline Pred. P 0.033 (at x-bar) & Pred. P 0.023 (at x-bar) & Pred. P 0.032 (at x-bar) & Pred. P 0.027 (at x-bar) \\
\hline
\end{tabular}


Figure 2a Unemployment spell survival functions, males, Australia, 1993-94 to 1996-97 SIHC. Spells defined to end with any exit from unemployment.

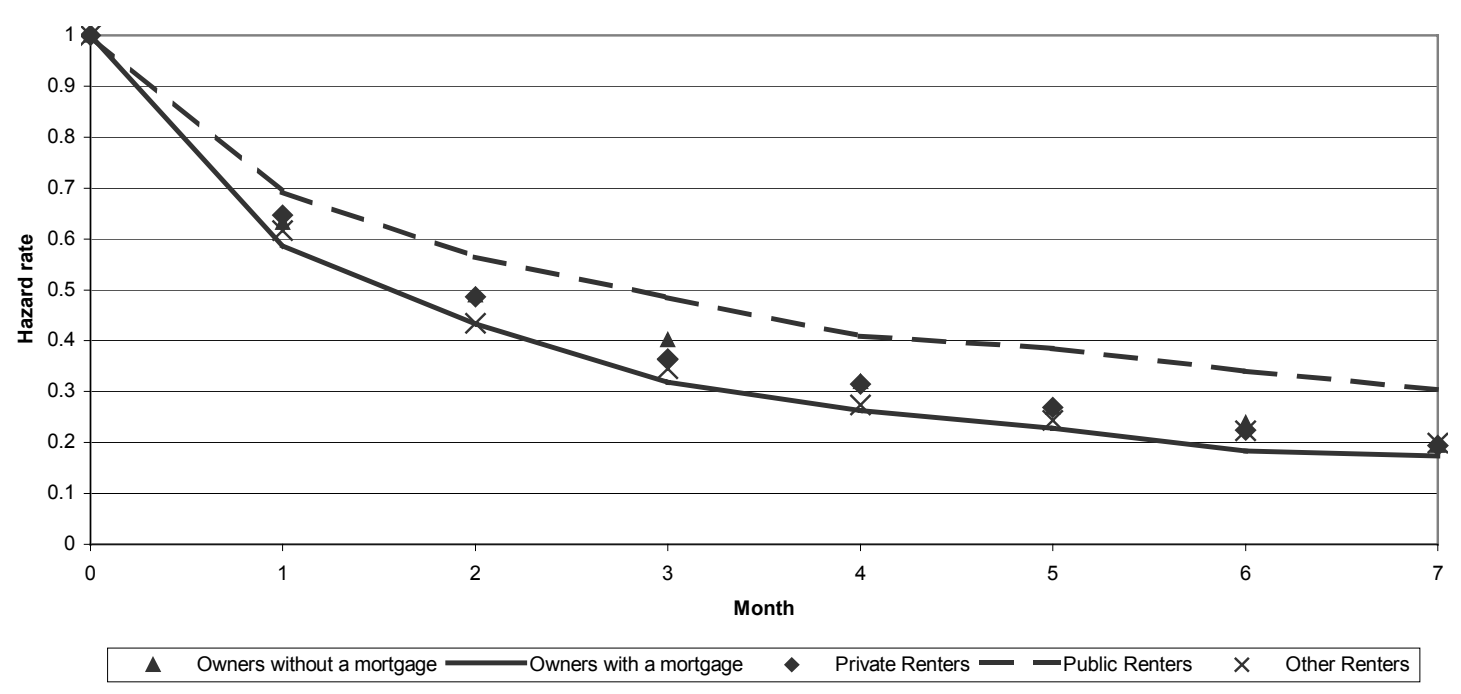


Figure 2b Unemployment spell survival functions, females, Australia, 1993-94 to 1996-97 SIHC. Spells defined to end with any exit from unemployment

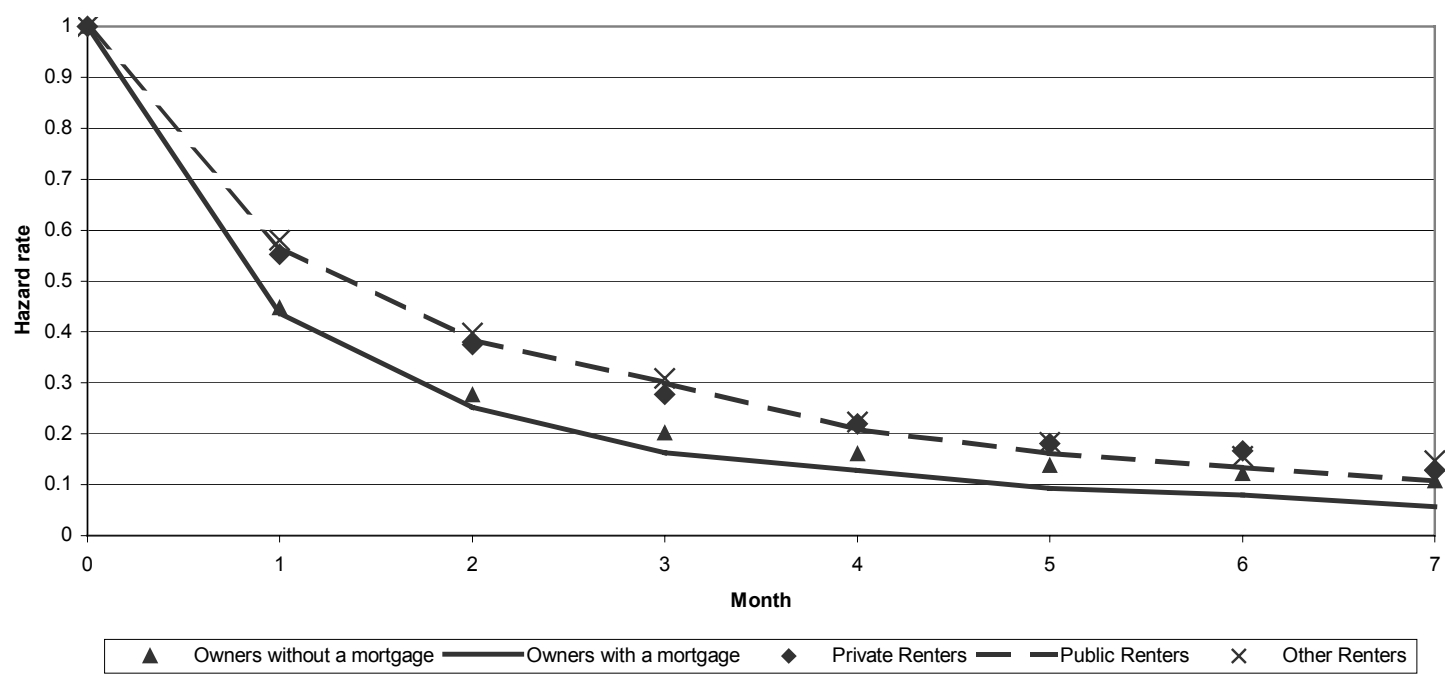

Figure 2c Unemployment spell survival functions, males, Australia, 1993-94 to 1996-97 SIHC. Spells end on re-employment.

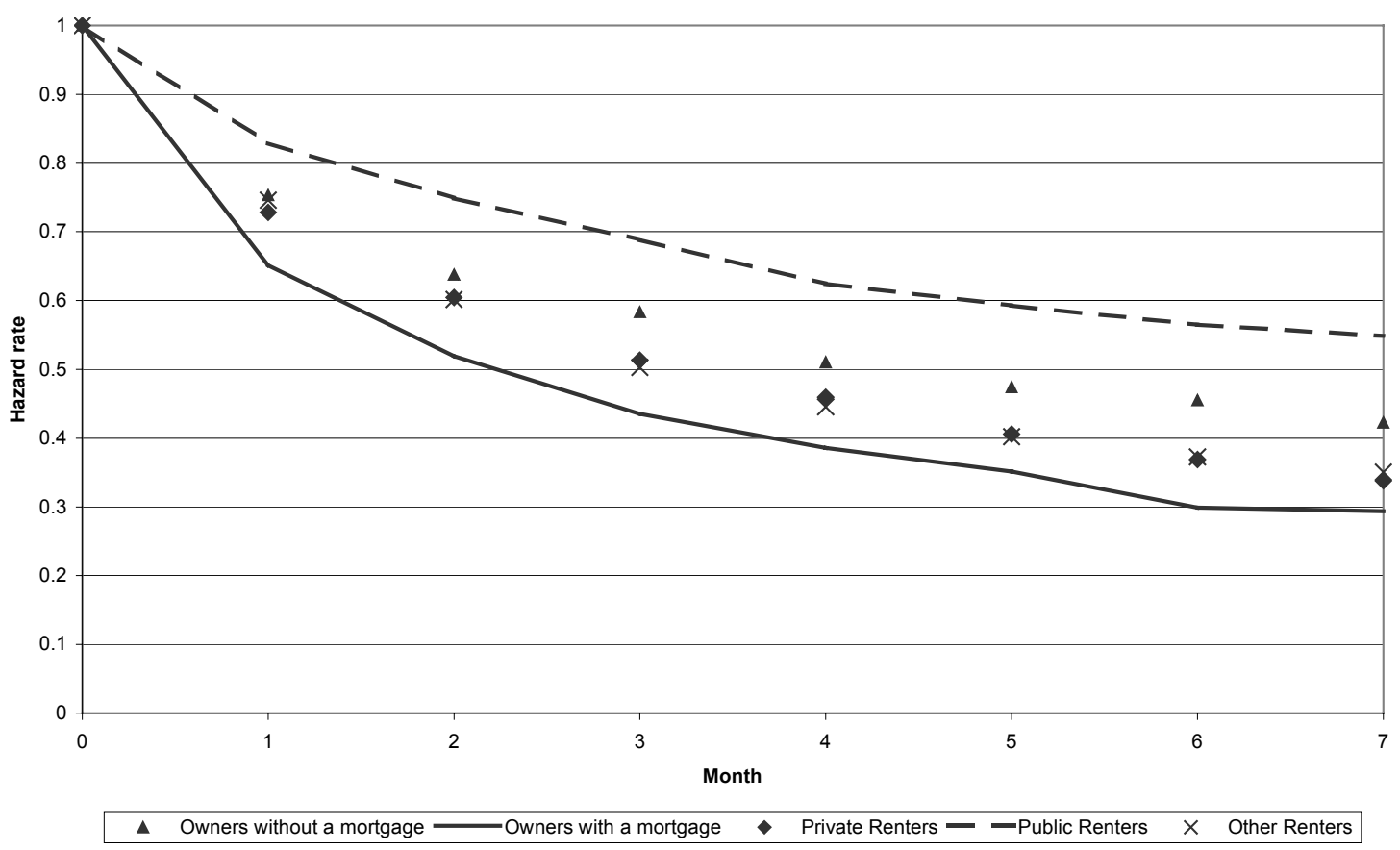


Figure 2d Unemployment spell survival functions, females, Australia, 1993-94 to 1996-97 SIHC. Spells end on re-employment.

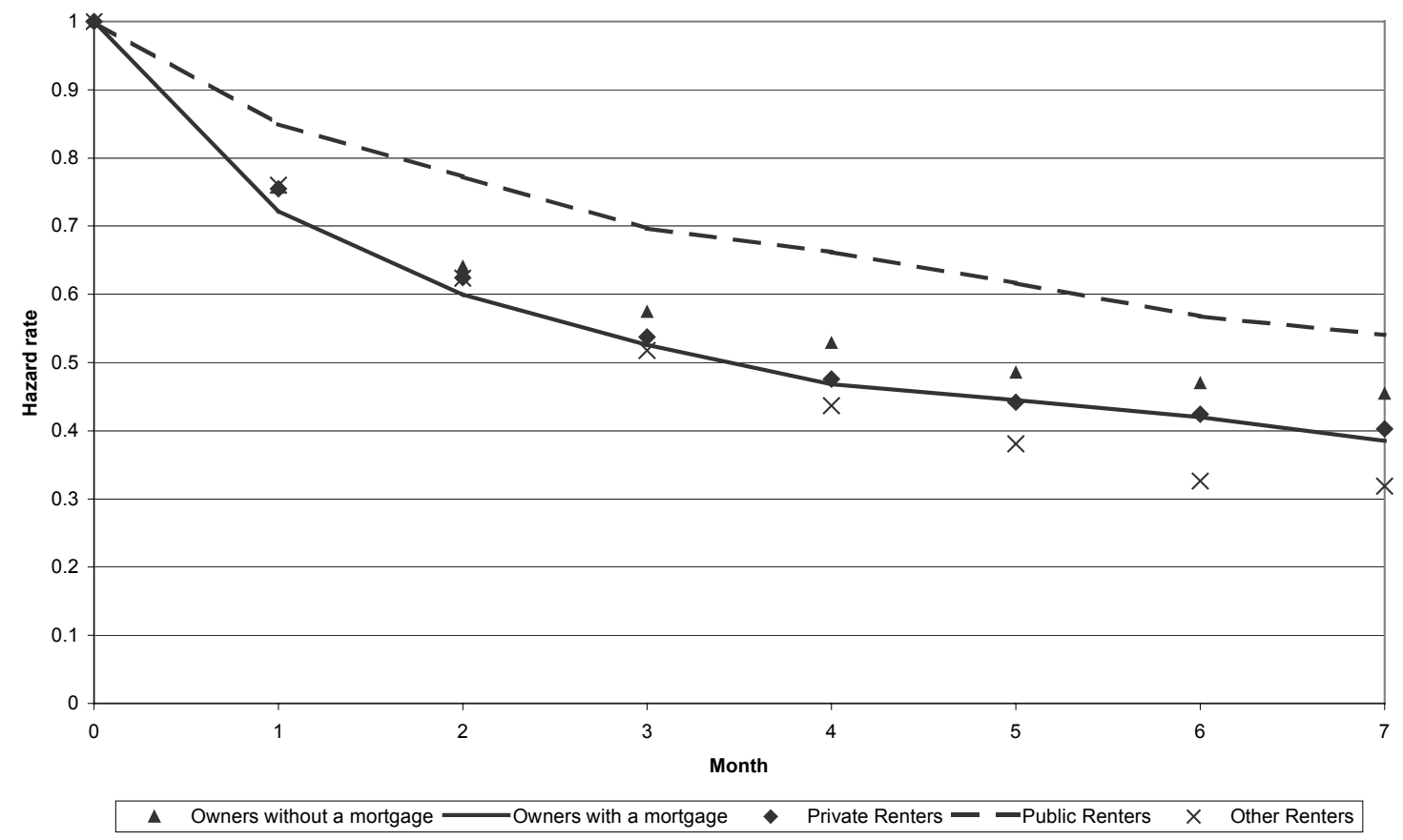

Figure 2e Unemployment spell survival functions, males, Australia, 1993-94 to 1996-97 SIHC. Spells end on full-time re-employment.

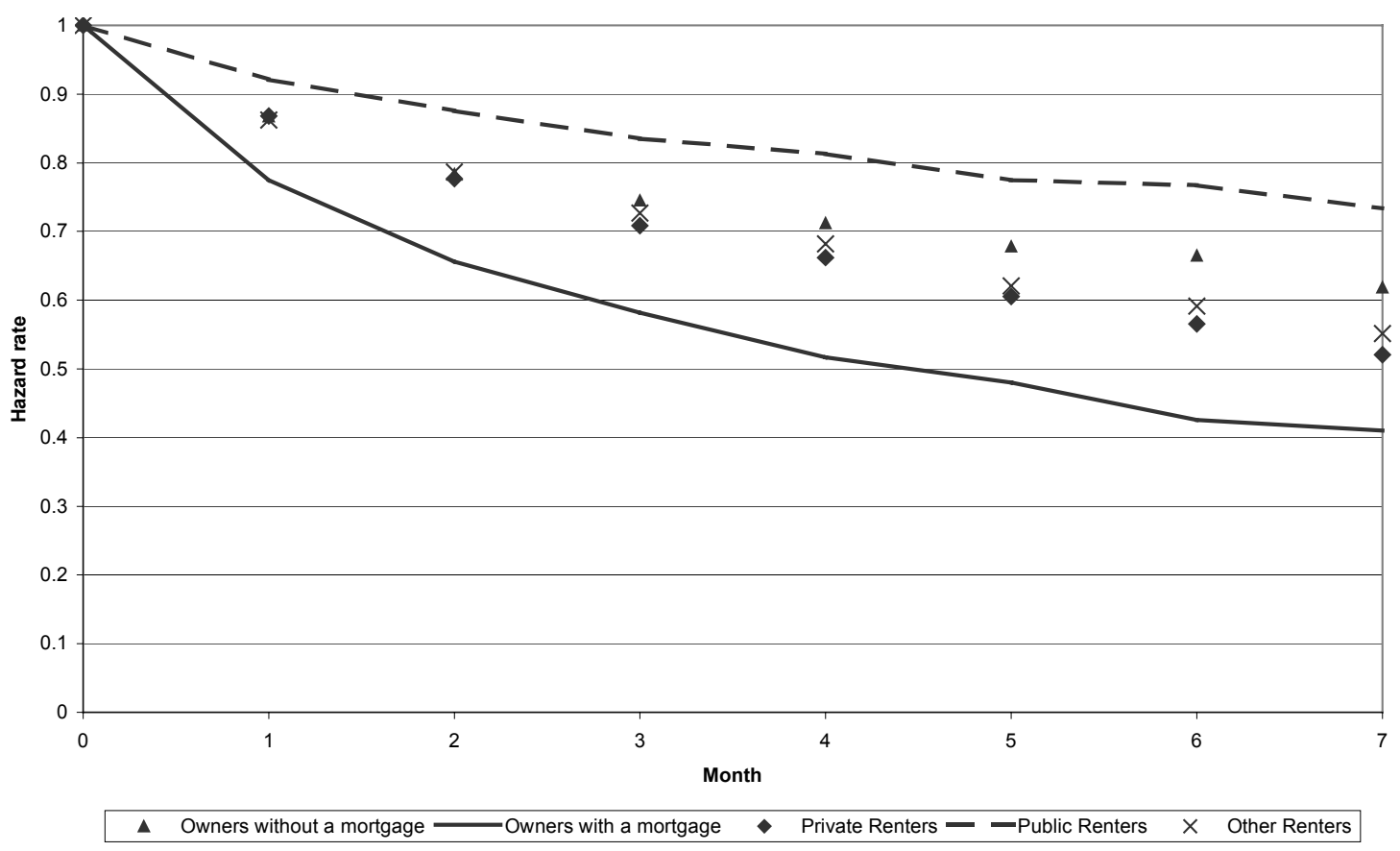


Figure 2 f Unemployment spell survival functions, females, Australia, 1993-94 to 1996-97 SIHC. Spells end on full-time re-employment.

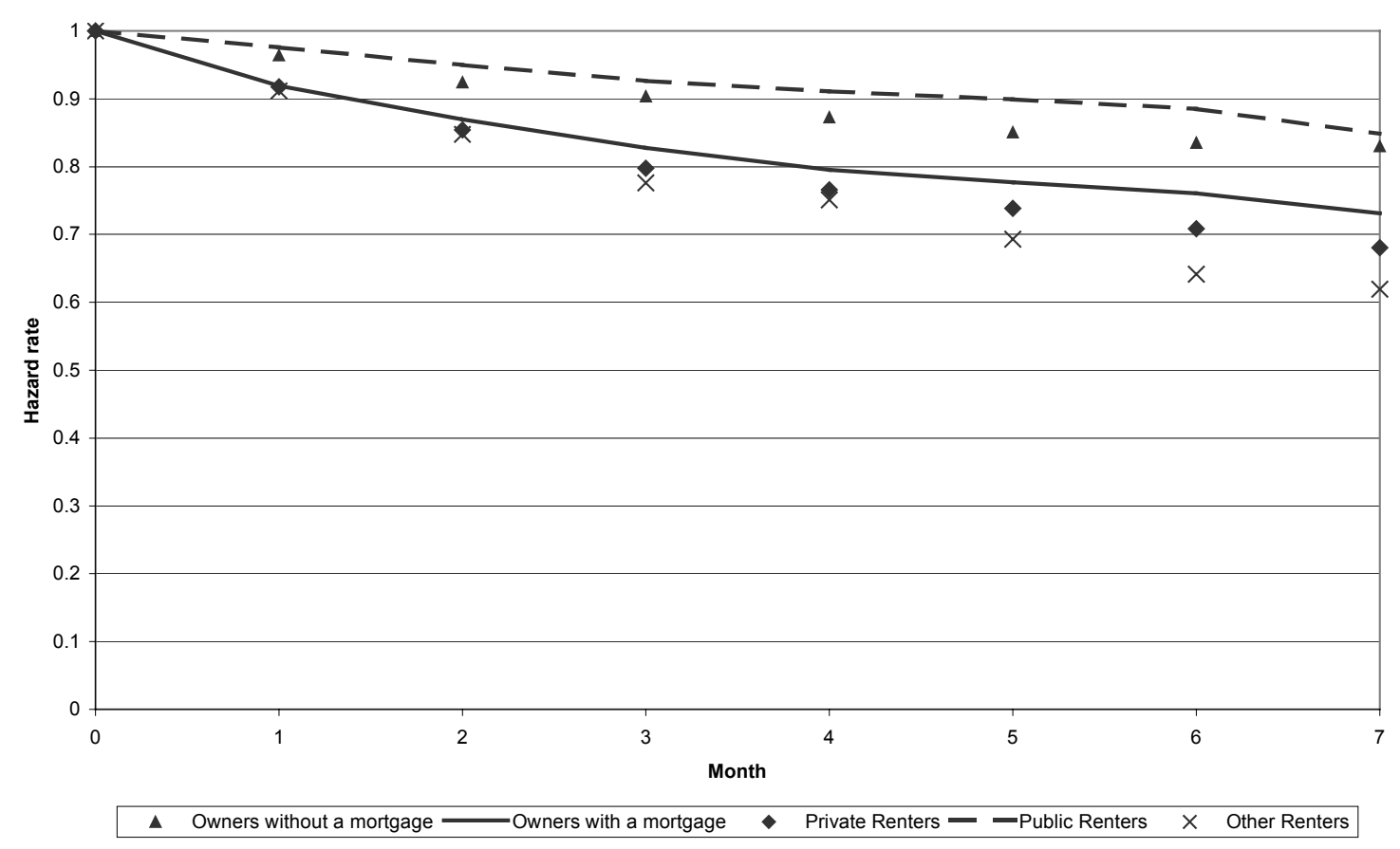


Figure 2g Unemployment spell survival functions, males, Australia, 1993-94 to 1996-97 SIHC. Job Losers in data window. Spells end on full-time re-employment.

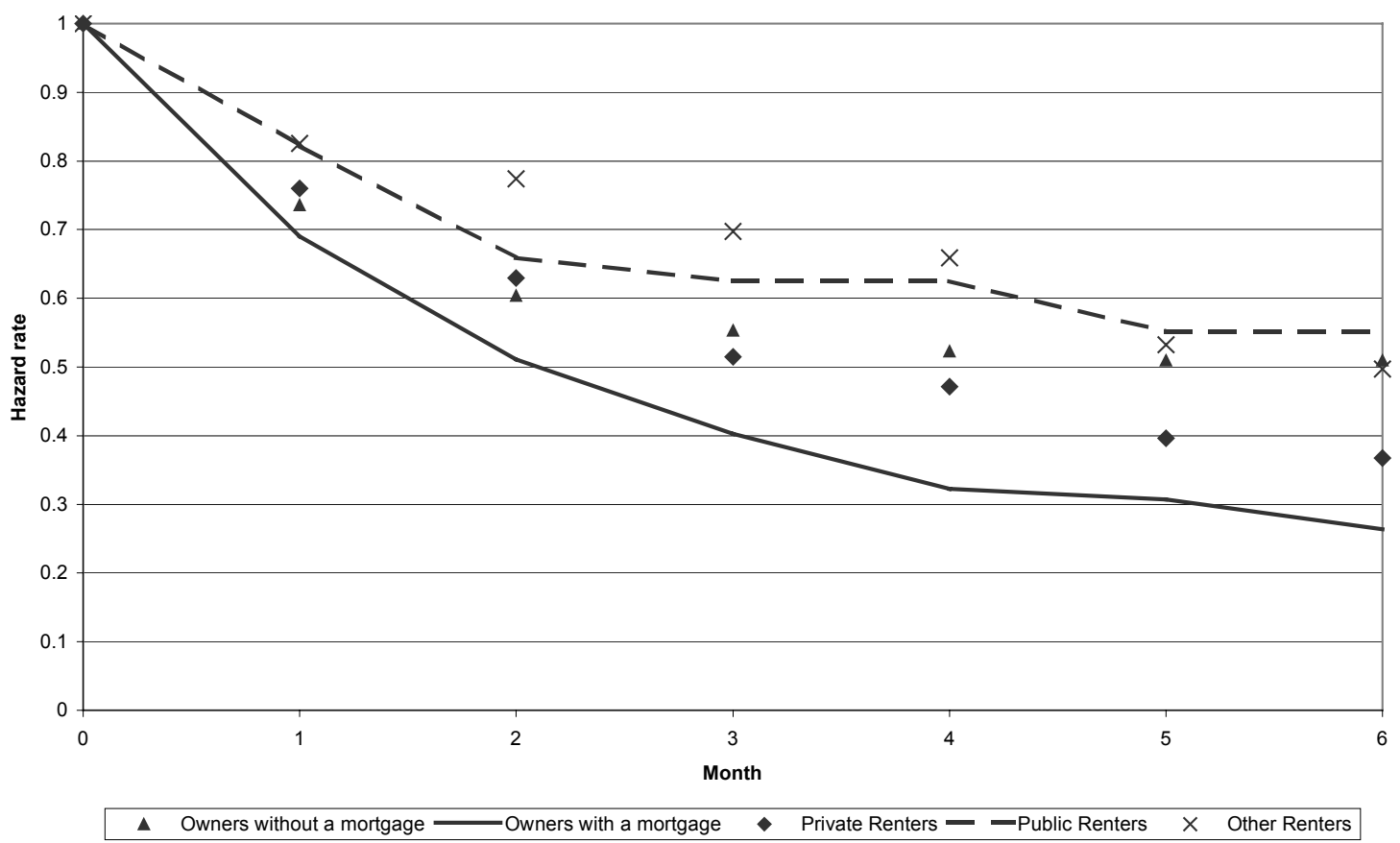

Figure $2 \mathrm{~h}$ Unemployment spell survival functions, females, Australia, 1993-94 to 1996-97 SIHC. Job Losers in data window. Spells end on full-time re-employment.

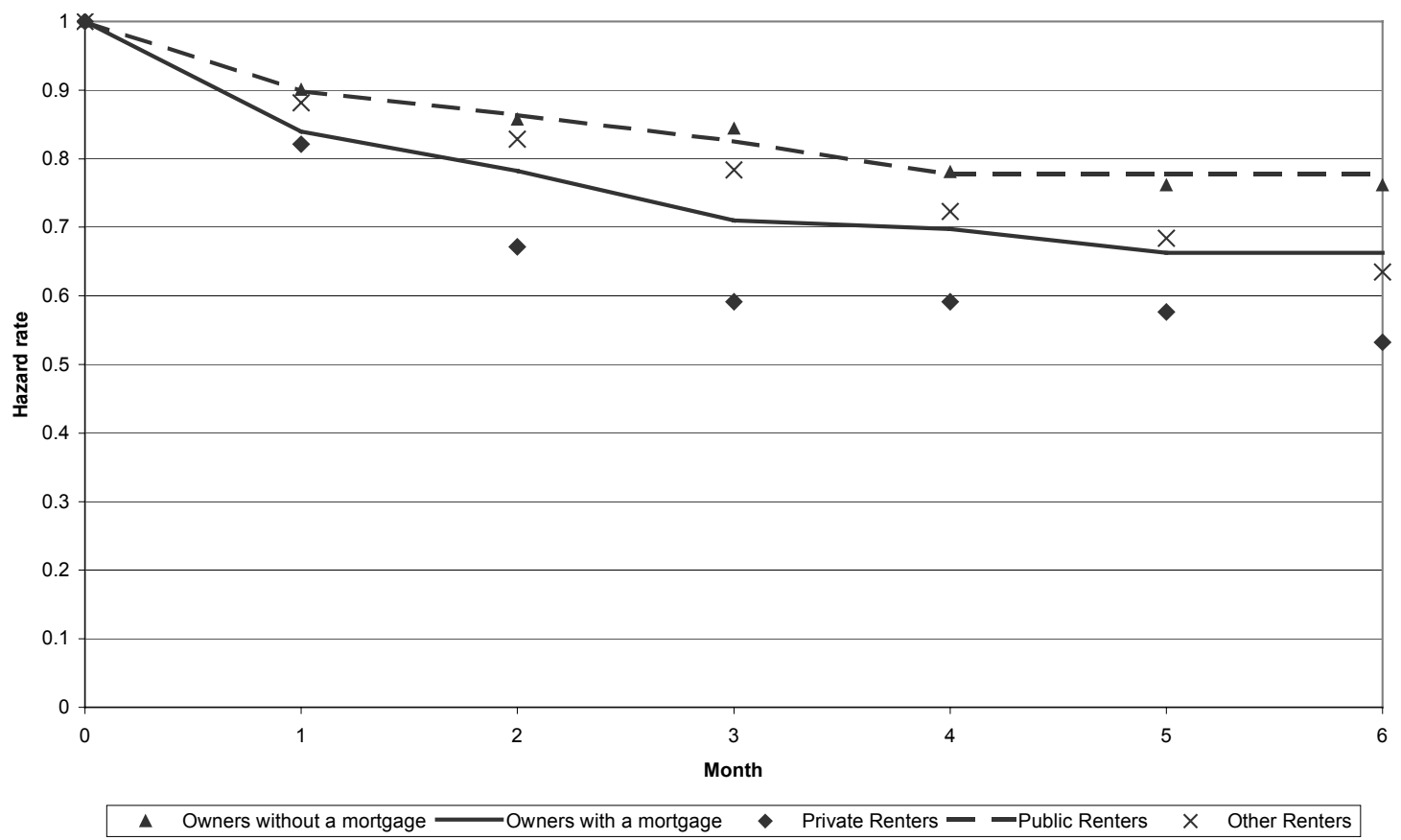


Table 6 Cox Proportional Hazard Models: Unemployment Spells and Home Ownership Effects, 1993-94 to 1996-97 SIHC

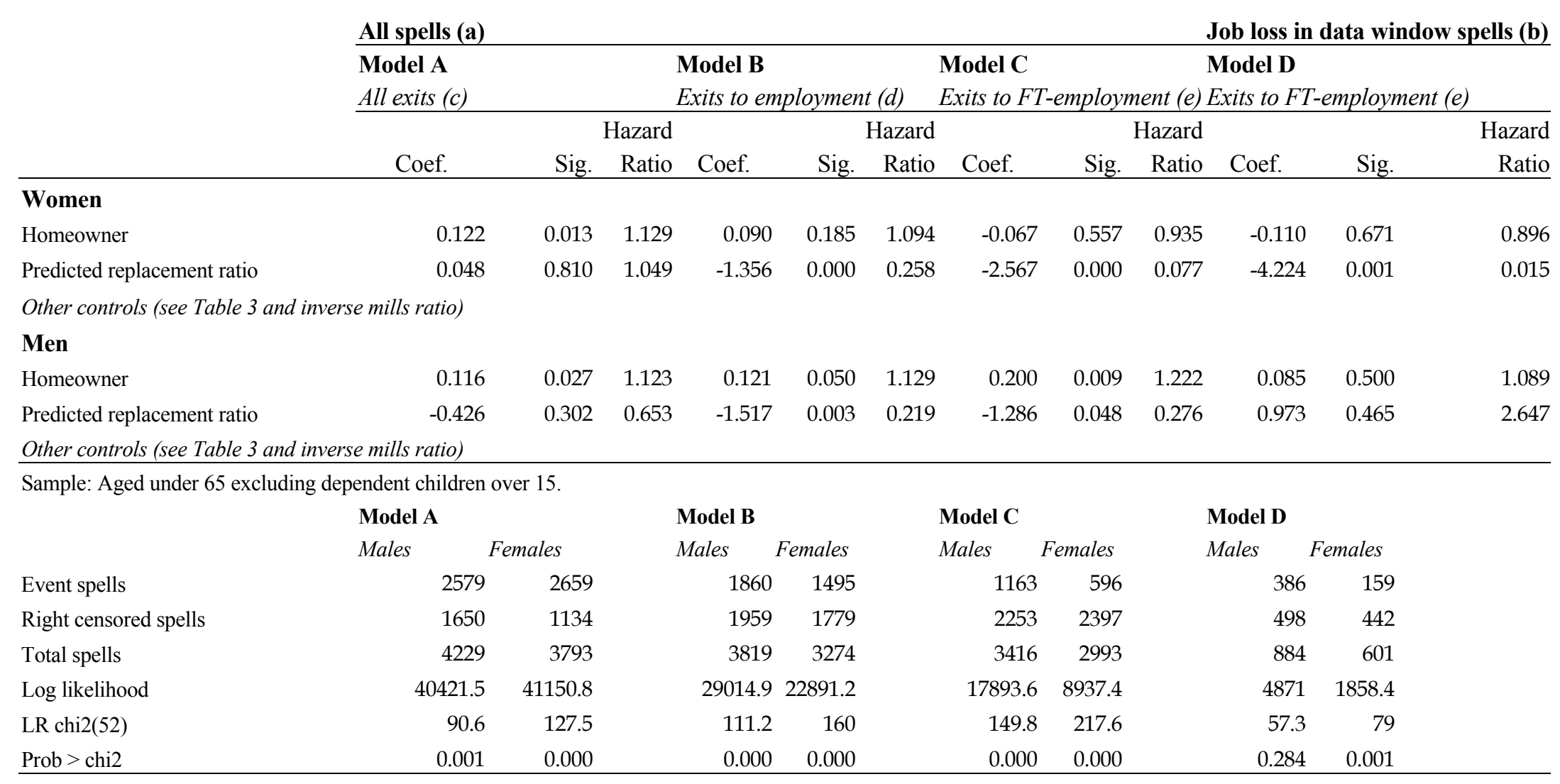

(a) Includes left uncensored and left censored spells of unemployment and all transitions into unemployment (i.e., transitions from both employment and not in the labor force included).

(b) Spells of unemployment of those who were employed in the first month of the data window. All left censored spells of unemployment excluded.

(c) The spell ends when a transition is made from unemployment to any other labor force state.

(d) The spell ends when a transition is made from unemployment to employment (both part and full-time employment.

(e) The spell ends when a transition is made from unemployment to full-time employment. 
Table 7 Cox Proportional Hazard Models: Unemployment Spells and Housing Tenure Effects, 1993-94 to 1996-97 SIHC

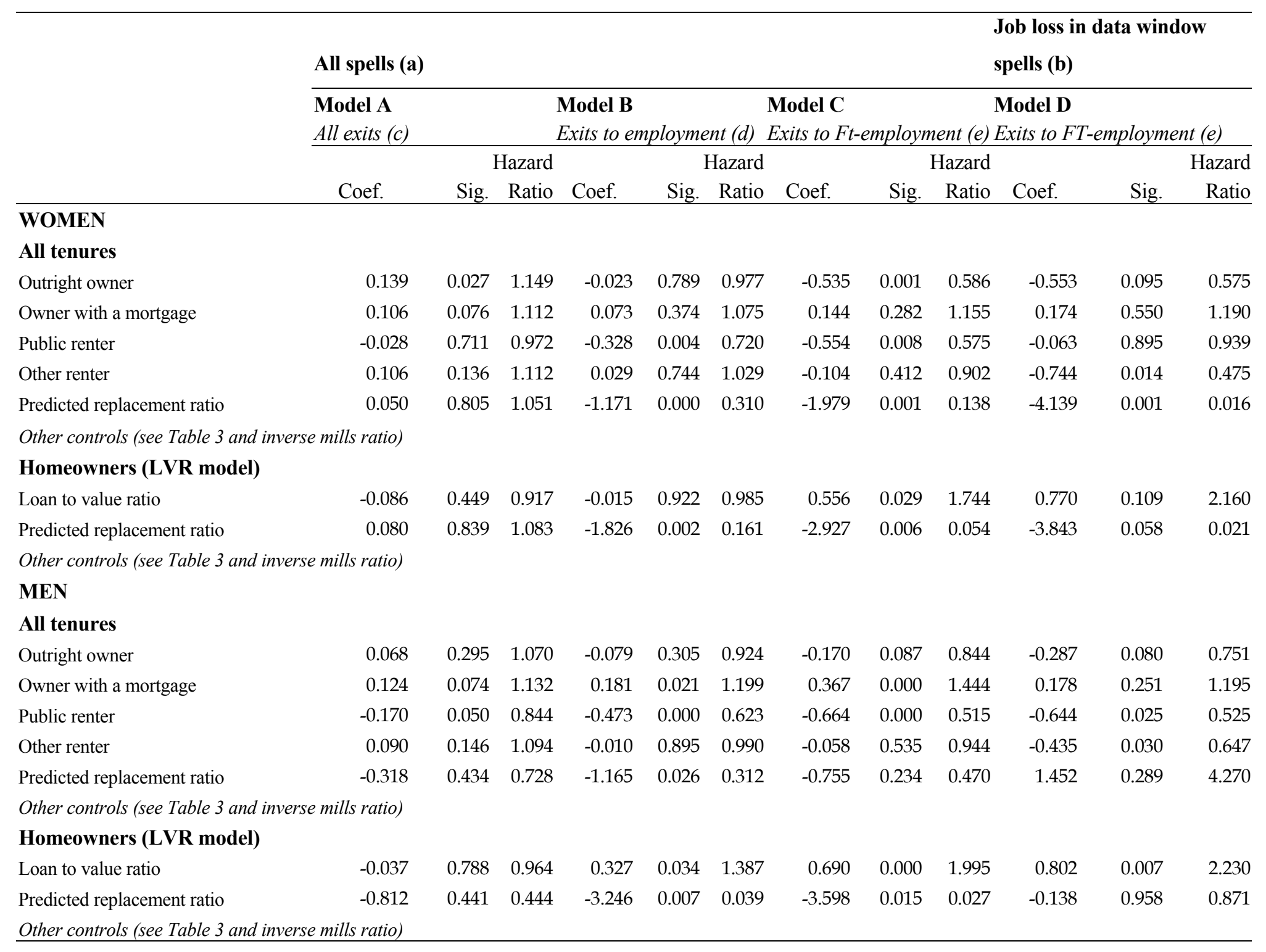


Sample: Aged under 65 excluding dependent children over 15.

\begin{tabular}{|c|c|c|c|c|c|c|c|c|}
\hline \multirow{3}{*}{$\begin{array}{l}\text { All housing tenures } \\
\text { Event spells }\end{array}$} & \multicolumn{2}{|l|}{ Model A } & \multicolumn{2}{|l|}{ Model B } & \multicolumn{2}{|l|}{ Model C } & \multicolumn{2}{|l|}{ Model D } \\
\hline & Males & Females & Males & Females & Males & Females & Males & Females \\
\hline & 2579 & 2659 & 1860 & 1495 & 1163 & 596 & 386 & 159 \\
\hline Total spells & 4229 & 3793 & 3819 & 3274 & 3416 & 2993 & 884 & 601 \\
\hline Log likelihood & 40413.5 & 41148.1 & 28985.6 & 22880.8 & 17846.9 & 8910.9 & 4854.7 & 1846.0 \\
\hline LR chi2(55) & 98.3 & 130.2 & 138.7 & 170.0 & 196.7 & 241.6 & 72.8 & 92.6 \\
\hline Homeowners (LVR models) & Males & Females & Males & Females & Males & Females & Males & Females \\
\hline Event spells & 859 & 1089 & 614 & 579 & 408 & 195 & 178 & 67 \\
\hline Right censored spells & 473 & 353 & 595 & 646 & 681 & 933 & 209 & 233 \\
\hline Prob $>$ chi 2 & 0.300 & 0.184 & 0.019 & 0.011 & 0.000 & 0.001 & 0.453 & 0.178 \\
\hline
\end{tabular}

(a) Includes left uncensored and left censored spells of unemployment and all transitions into unemployment (i.e., transitions from both employment and not in the labor force included).

(b) Spells of unemployment of those who were employed in the first month of the data window. All left censored spells of unemployment excluded.

(c) The spell ends when a transition is made from unemployment to any other labor force state.

(d) The spell ends when a transition is made from unemployment to employment (both part and full-time employment.

(e) The spell ends when a transition is made from unemployment to full-time employment. 
Appendix Table 1 Probability of an Income Unit Being a Home Owner, 1993-94 to 1996-97 SIHC, Probit Model

\begin{tabular}{|c|c|c|c|c|}
\hline & Coef. & Std. Err. & Sig. & $\mathrm{DF} / \mathrm{dx}$ \\
\hline Constant & -3.042 & 0.124 & -24.44 & \\
\hline Earned Income of the Income Unit & 1.17E-05 & 3.92E-07 & 29.87 & $1.560 \mathrm{E}-07$ \\
\hline Sydney & 0.035 & 0.043 & 0.83 & 0.014 \\
\hline Country NSW & 0.219 & 0.048 & 4.57 & 0.087 \\
\hline Melbourne & 0.333 & 0.042 & 7.91 & 0.132 \\
\hline Country Victoria & 0.449 & 0.054 & 8.38 & 0.176 \\
\hline Brisbane & 0.230 & 0.047 & 4.89 & 0.092 \\
\hline Country Queensland & 0.225 & 0.046 & 4.87 & 0.090 \\
\hline Adelaide & 0.375 & 0.047 & 8.02 & 0.148 \\
\hline Country South Australia & 0.282 & 0.064 & 4.37 & 0.112 \\
\hline Perth & 0.411 & 0.045 & 9.07 & 0.162 \\
\hline Country Western Australia & 0.158 & 0.061 & 2.57 & 0.063 \\
\hline Hobart & 0.270 & 0.066 & 4.11 & 0.107 \\
\hline Country Tasmania & 0.418 & 0.058 & 7.25 & 0.164 \\
\hline Couple income unit & 0.717 & 0.087 & 8.23 & 0.280 \\
\hline Single female income unit & 0.124 & 0.030 & 4.16 & 0.050 \\
\hline Sole parent male income unit & 0.160 & 0.089 & 1.80 & 0.064 \\
\hline Sole parent female income unit & 0.159 & 0.045 & 3.56 & 0.063 \\
\hline Age -20 to 24 & 0.652 & 0.124 & 5.26 & 0.251 \\
\hline Age -25 to 29 & 1.210 & 0.122 & 9.94 & 0.423 \\
\hline Age -30 to 34 & 1.634 & 0.122 & 13.41 & 0.517 \\
\hline Age -35 to 39 & 1.850 & 0.122 & 15.13 & 0.551 \\
\hline Age -40 to 44 & 2.062 & 0.123 & 16.80 & 0.577 \\
\hline Age -45 to 49 & 2.218 & 0.123 & 18.03 & 0.590 \\
\hline Age -50 to 54 & 2.405 & 0.124 & 19.41 & 0.588 \\
\hline Age -55 to 59 & 2.655 & 0.125 & 21.27 & 0.590 \\
\hline Age -60 to 64 & 2.779 & 0.125 & 22.15 & 0.587 \\
\hline Higher degree & -0.143 & 0.066 & -2.18 & -0.057 \\
\hline
\end{tabular}


Appendix Table 1 Probability of an Income Unit Being a Home Owner, 1993-94 to 1996-97 SIHC, Probit Model

\begin{tabular}{lcrrr} 
& Coef. & Std. Err. & Sig. & DF $/ \mathrm{dx}$ \\
\hline Postgraduate diploma & 0.206 & 0.061 & 3.39 & 0.082 \\
Bachelor degree & 0.114 & 0.033 & 3.42 & 0.045 \\
Undergraduate diploma & 0.094 & 0.055 & 1.71 & 0.037 \\
Associate diploma & 0.178 & 0.038 & 4.63 & 0.071 \\
Skilled vocational & 0.201 & 0.024 & 8.54 & 0.080 \\
Basic vocational & 0.078 & 0.054 & 1.45 & 0.031 \\
Married or defacto & 0.265 & 0.087 & 3.05 & 0.105 \\
Separated, widowed, divorced & 0.215 & 0.032 & 6.83 & 0.086 \\
Number of dependent children in the unit & 0.062 & 0.011 & 5.76 & 0.025 \\
Country of birth - Oceania & -0.354 & 0.055 & -6.40 & -0.137 \\
Country of birth - Europe + former USSR & -0.036 & 0.026 & -1.38 & -0.014 \\
Country of birth - Middle East + N.Africa & -0.188 & 0.079 & -2.38 & -0.074 \\
Country of birth - S.E. Asia & -0.146 & 0.057 & -2.58 & -0.058 \\
Country of birth - N.E. Asia & -0.268 & 0.085 & -3.16 & -0.105 \\
Country of birth - Southern Asia & -0.253 & 0.093 & -2.73 & -0.099 \\
Country of birth - North America & -0.379 & 0.126 & -3.02 & -0.146 \\
\hline Country of birth - Sth/Cntr America+Carib. & -0.498 & 0.125 & -4.00 & -0.188 \\
Country of birth - Africa (excl. N. Africa) & -0.374 & 0.103 & -3.62 & -0.144 \\
\hline Dependent Varable
\end{tabular}

Dependent Variable Home Owner =1, Not Home Owner $=0$

Quarterly time dummies included in a preliminary equation but were insignificant and dropped from the final probit used to predict homeownership.

N=29279 Income Units. Sample: Reference Person Aged under 65.

$\begin{array}{ll}\text { Log likelihood }=-12331.3 & \text { Obs. P } 0.5118 \\ \text { LR chi2 }(40)=15910.4 & \text { Pred. P .478067 (at x-bar) } \\ \text { Prob }>\text { chi2 }=0.0000 & \\ \text { Pseudo R2 }=0.3921 & \end{array}$


Appendix Table 2 Multinomial Logit Model of Tenure Outcomes, 1993-94 to 1996-97 SIHC.

\begin{tabular}{|c|c|c|c|c|c|c|c|c|}
\hline & \multicolumn{6}{|c|}{ Owner with a } & & \\
\hline & \multicolumn{2}{|c|}{ Outright Owner } & \multicolumn{2}{|c|}{ Mortgage } & \multicolumn{2}{|c|}{ Public Renter } & \multicolumn{2}{|c|}{ Other tenure } \\
\hline & Coef. & Sig. & Coef. & Sig. & Coef. & Sig. & Coef. & Sig. \\
\hline Constant & -6.463 & 0.000 & -5.813 & 0.000 & -2.880 & 0.000 & -0.229 & 0.088 \\
\hline Earned Income of the Income Unit & 1.440E-05 & 0.000 & $1.970 \mathrm{E}-05$ & 0.000 & $-3.540 \mathrm{E}-05$ & 0.000 & $-8.500 \mathrm{E}-06$ & 0.000 \\
\hline Sydney & 0.161 & 0.109 & -0.307 & 0.000 & -1.379 & 0.000 & 0.112 & 0.267 \\
\hline Country NSW & 0.562 & 0.000 & -0.069 & 0.487 & -1.480 & 0.000 & 0.319 & 0.005 \\
\hline Melbourne & 0.641 & 0.000 & 0.258 & 0.002 & -1.596 & 0.000 & 0.370 & 0.000 \\
\hline Country Victoria & 0.959 & 0.000 & 0.352 & 0.001 & -1.576 & 0.000 & 0.339 & 0.007 \\
\hline Brisbane & 0.288 & 0.009 & 0.058 & 0.536 & -1.459 & 0.000 & -0.147 & 0.194 \\
\hline Country Queensland & 0.358 & 0.001 & -0.148 & 0.117 & -2.331 & 0.000 & -0.137 & 0.224 \\
\hline Adelaide & 0.776 & 0.000 & 0.521 & 0.000 & -0.453 & 0.000 & 0.097 & 0.391 \\
\hline Country South Australia & 1.046 & 0.000 & 0.408 & 0.004 & -0.296 & 0.101 & 0.843 & 0.000 \\
\hline Perth & 0.567 & 0.000 & 0.434 & 0.000 & -1.342 & 0.000 & -0.092 & 0.407 \\
\hline Country Western Australia & 0.303 & 0.034 & -0.044 & 0.725 & -1.427 & 0.000 & 0.180 & 0.230 \\
\hline Hobart & 0.502 & 0.001 & 0.313 & 0.017 & -0.559 & 0.002 & -0.165 & 0.305 \\
\hline Country Tasmania & 0.969 & 0.000 & 0.376 & 0.002 & -0.937 & 0.000 & 0.048 & 0.733 \\
\hline Couple income unit & 1.303 & 0.000 & 1.120 & 0.000 & 0.850 & 0.005 & -0.654 & 0.003 \\
\hline Single female income unit & 0.387 & 0.000 & 0.255 & 0.000 & 0.468 & 0.000 & 0.057 & 0.238 \\
\hline Sole parent male income unit & 0.321 & 0.125 & 0.389 & 0.030 & 1.023 & 0.000 & -0.519 & 0.121 \\
\hline Sole parent female income unit & 0.607 & 0.000 & 0.454 & 0.000 & 1.377 & 0.000 & -1.110 & 0.000 \\
\hline Age -20 to 24 & 0.447 & 0.358 & 2.156 & 0.000 & 0.879 & 0.000 & -0.612 & 0.000 \\
\hline Age -25 to 29 & 1.635 & 0.000 & 3.106 & 0.000 & 1.591 & 0.000 & -0.918 & 0.000 \\
\hline Age -30 to 34 & 2.746 & 0.000 & 3.748 & 0.000 & 1.960 & 0.000 & -0.889 & 0.000 \\
\hline Age -35 to 39 & 3.532 & 0.000 & 4.003 & 0.000 & 2.248 & 0.000 & -0.894 & 0.000 \\
\hline Age - 40 to 44 & 4.281 & 0.000 & 4.230 & 0.000 & 2.431 & 0.000 & -0.724 & 0.000 \\
\hline Age -45 to 49 & 4.872 & 0.000 & 4.357 & 0.000 & 2.762 & 0.000 & -0.695 & 0.000 \\
\hline Age -50 to 54 & 5.581 & 0.000 & 4.511 & 0.000 & 3.253 & 0.000 & -0.420 & 0.002 \\
\hline Age - 55 to 59 & 6.201 & 0.000 & 4.584 & 0.000 & 3.335 & 0.000 & -0.392 & 0.010 \\
\hline Age -60 to 64 & 6.773 & 0.000 & 4.287 & 0.000 & 3.709 & 0.000 & -0.006 & 0.972 \\
\hline Higher degree & -0.426 & 0.002 & -0.440 & 0.001 & -2.877 & 0.000 & -0.291 & 0.170 \\
\hline Postgraduate diploma & 0.120 & 0.380 & 0.340 & 0.005 & -1.408 & 0.001 & 0.007 & 0.968 \\
\hline
\end{tabular}


Appendix Table 2 Multinomial Logit Model of Tenure Outcomes, 1993-94 to 1996-97 SIHC.

\begin{tabular}{|c|c|c|c|c|c|c|c|c|}
\hline & \multicolumn{6}{|c|}{ Owner with a } & & \\
\hline & \multicolumn{2}{|c|}{ Outright Owner } & \multicolumn{2}{|c|}{ Mortgage } & \multicolumn{2}{|c|}{ Public Renter } & \multicolumn{2}{|c|}{ Other tenure } \\
\hline & Coef. & Sig. & Coef. & Sig. & Coef. & Sig. & Coef. & Sig. \\
\hline Bachelor degree & 0.089 & 0.237 & 0.111 & 0.092 & -1.513 & 0.000 & 0.117 & 0.125 \\
\hline Undergraduate diploma & -0.047 & 0.693 & 0.141 & 0.199 & -1.110 & 0.000 & 0.282 & 0.046 \\
\hline Associate diploma & 0.183 & 0.032 & 0.253 & 0.001 & -0.734 & 0.000 & 0.064 & 0.493 \\
\hline Skilled vocational & 0.214 & 0.000 & 0.287 & 0.000 & -0.492 & 0.000 & -0.099 & 0.119 \\
\hline Basic vocational & 0.032 & 0.797 & 0.112 & 0.301 & -0.151 & 0.318 & -0.182 & 0.089 \\
\hline Married or defacto & 0.078 & 0.695 & 0.530 & 0.004 & -0.077 & 0.793 & -0.129 & 0.535 \\
\hline Separated, widowed, divorced & -0.111 & 0.135 & 0.413 & 0.000 & -0.021 & 0.823 & -0.673 & 0.000 \\
\hline Number of dependent children in the unit & 0.186 & 0.000 & 0.171 & 0.000 & 0.334 & 0.000 & 0.039 & 0.407 \\
\hline Country of birth - Oceania & -0.964 & 0.000 & -0.577 & 0.000 & -0.183 & 0.310 & -0.601 & 0.000 \\
\hline Country of birth - Europe + former USSR & -0.112 & 0.048 & -0.094 & 0.086 & -0.179 & 0.057 & -0.160 & 0.046 \\
\hline Country of birth - Middle East + N.Africa & -0.389 & 0.026 & -0.309 & 0.057 & -0.197 & 0.390 & -0.166 & 0.445 \\
\hline Country of birth - S.E. Asia & -0.402 & 0.003 & -0.115 & 0.304 & 0.345 & 0.033 & -0.099 & 0.437 \\
\hline Country of birth - N.E. Asia & -0.381 & 0.042 & -0.629 & 0.000 & -1.127 & 0.004 & 0.258 & 0.147 \\
\hline Country of birth - Southern Asia & -0.760 & 0.000 & -0.356 & 0.051 & -0.066 & 0.853 & -0.192 & 0.448 \\
\hline Country of birth - North America & -0.864 & 0.003 & -0.681 & 0.005 & -1.866 & 0.071 & -0.075 & 0.794 \\
\hline Country of birth - Sth/Cntr America+Carib. & -1.252 & 0.000 & -0.538 & 0.025 & 0.296 & 0.378 & 0.125 & 0.634 \\
\hline Country of birth - Africa (excl. N. Africa) & -1.224 & 0.000 & -0.470 & 0.015 & -0.563 & 0.210 & -0.115 & 0.645 \\
\hline
\end{tabular}

Quarterly time dummies

Mixed Significance Generally Insignificant Generally Insignificant Generally Insignificant

Private Renter is the omitted tenure type category.

N=29279 Income Units. Sample: Reference Person Aged under 65.

Log likelihood $=-30533.327$

LR chi2 $(240)=24094.53$

Prob $>$ chi2 $=0.0000$

Pseudo R2 $=0.2829$ 


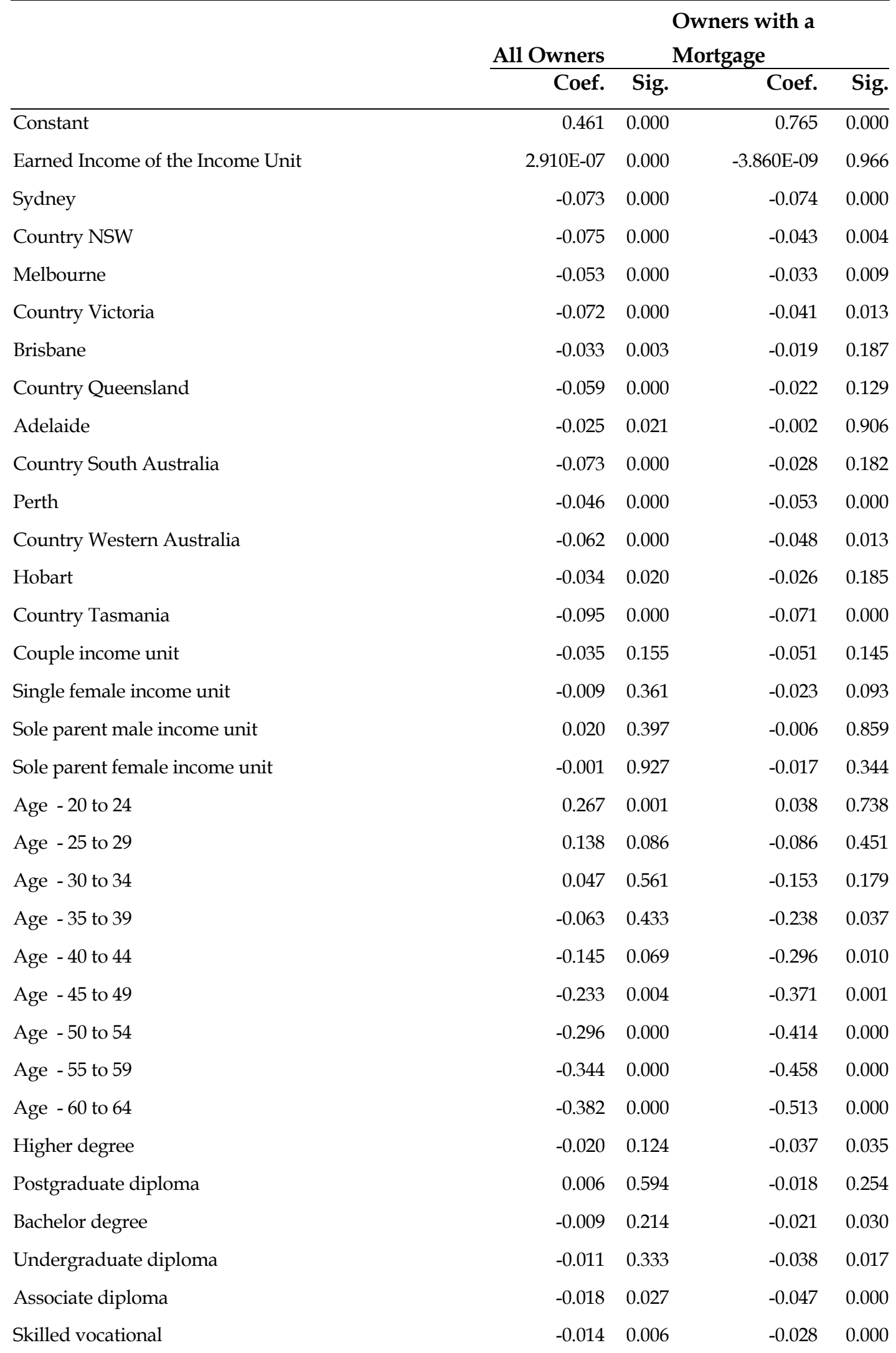


Appendix Table 3 Ordinary Least Squares Model of the Loan-to-Value Ratio, 1993-94 to 1996-97 SIHC.

\begin{tabular}{lrrrr}
\hline & \multicolumn{4}{c}{ Owners with a } \\
& All Owners & Mortgage \\
\cline { 2 - 5 } & Coef. & Sig. & Coef. & Sig. \\
\hline Basic vocational & 0.027 & 0.055 & 0.042 & 0.027 \\
Married or defacto & 0.058 & 0.021 & 0.024 & 0.509 \\
Separated, widowed, divorced & 0.045 & 0.000 & 0.018 & 0.176 \\
Number of dependent children in the unit & -0.013 & 0.000 & -0.014 & 0.000 \\
Country of birth - Oceania & 0.054 & 0.000 & 0.044 & 0.013 \\
Country of birth - Europe + former USSR & 0.019 & 0.000 & 0.038 & 0.000 \\
Country of birth - Middle East + N.Africa & 0.045 & 0.018 & 0.082 & 0.002 \\
Country of birth - S.E. Asia & 0.044 & 0.002 & 0.047 & 0.009 \\
Country of birth - N.E. Asia & -0.024 & 0.282 & 0.006 & 0.861 \\
Country of birth - Southern Asia & 0.114 & 0.000 & 0.138 & 0.000 \\
Country of birth - North America & 0.064 & 0.048 & 0.081 & 0.055 \\
Country of birth - Sth/Cntr America+Carib. & 0.150 & 0.000 & 0.176 & 0.000 \\
Country of birth - Africa (excl. N. Africa) & 0.072 & 0.002 & 0.050 & 0.078 \\
Quarterly time dummies & Generally Significant Generally Insignificant
\end{tabular}

Sample: Reference Person Aged under 65.

$\begin{array}{ll}\text { All Owners } & \text { Owners with a Mortg } \\ \mathrm{N}=14972 & \mathrm{~N}=7997 \\ \mathrm{~F}(60,14911)=105.56 & \mathrm{~F}(60,7936)=34.45 \\ \text { Prob }>\mathrm{F}=0.0000 & \text { Prob }>\mathrm{F}=0.0000 \\ \text { Adjusted } \mathrm{R} 2=0.2953 & \text { Adjusted } \mathrm{R} 2=0.2067\end{array}$

